\title{
الحوار الأسري : همارساته ومعوقاته داخل الأسرة السعودية وعلاقته ببعض المتغيرات
}

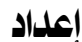 \\ د. منحــ حامد إبراهيم موسمـــ \\ أستاذ مساعد تخصص سكن وإدارة منزل

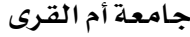

مجلة بحوث التربية النوعية - جامعة المنصورة

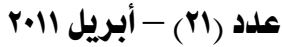




\section{الحوار الأسري : همارساته ومعوقاته داخل الأسرة السعودية وعلاقته ببعض المتغيرات}

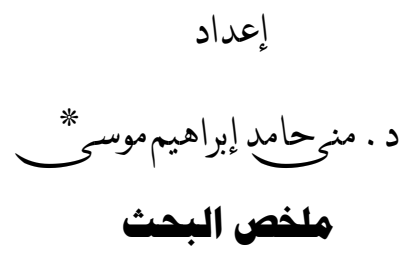

المقدمة والمشكلة البحثية: - مائية

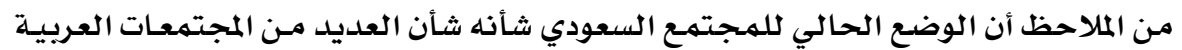

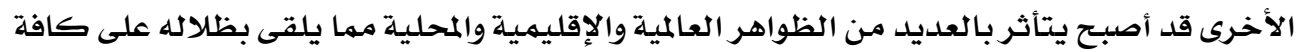

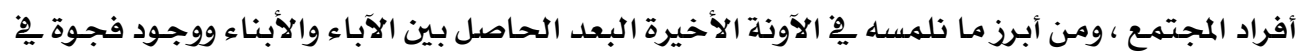

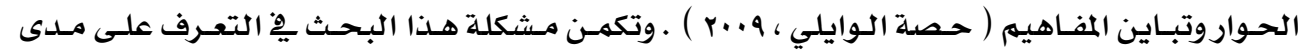

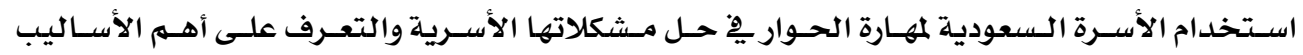

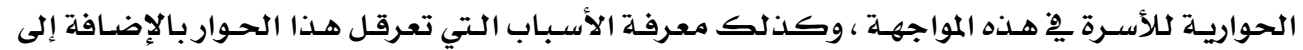

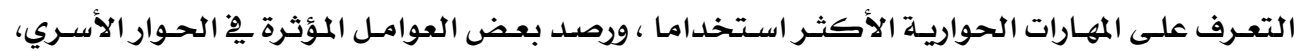

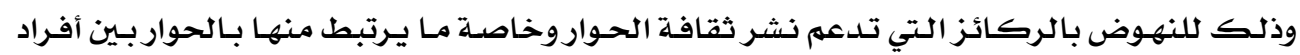

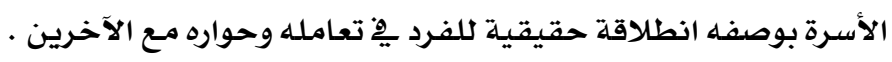

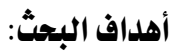

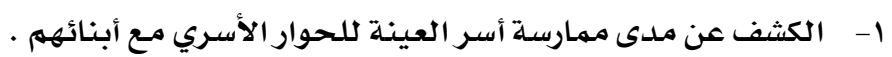

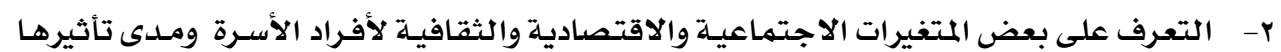

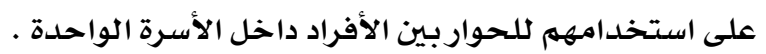

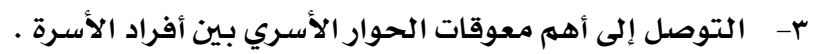

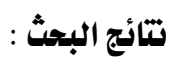

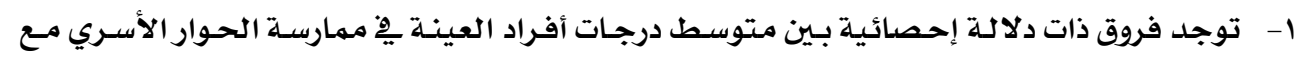

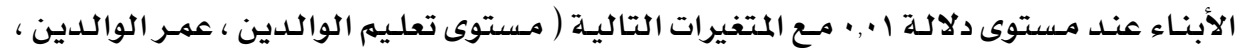

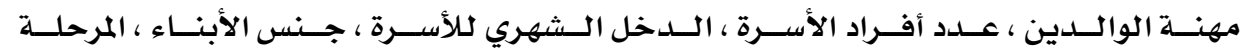
الدراسية لكلأبناء ) .

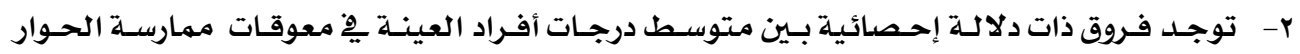

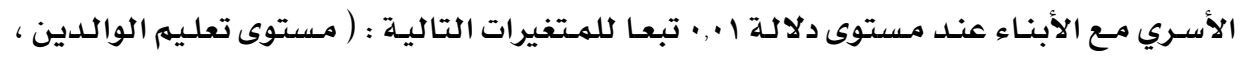
* أستاذ مساعد تخصص سكن وإدارة منزل جامعة أم القرى 


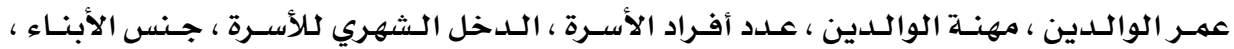

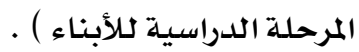

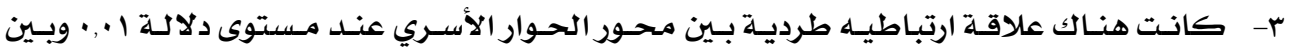

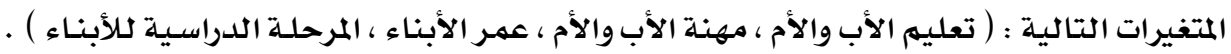

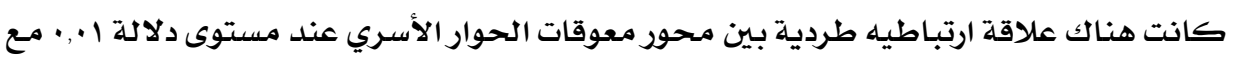
متغير عدد أفراد الأسرة .

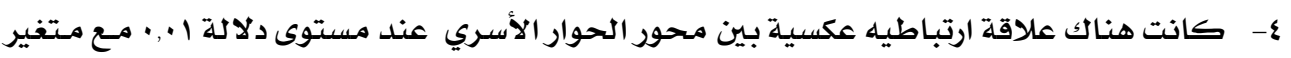

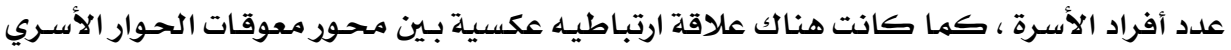

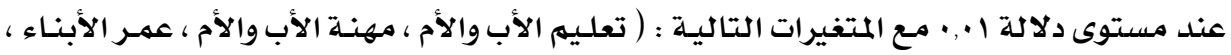

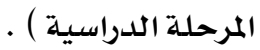

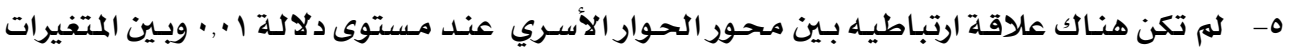

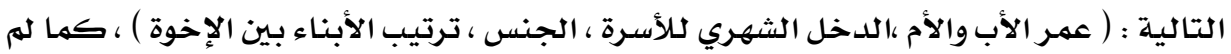

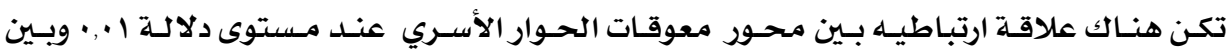

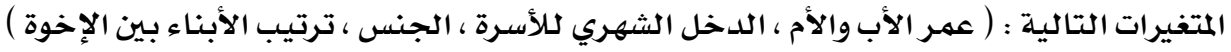

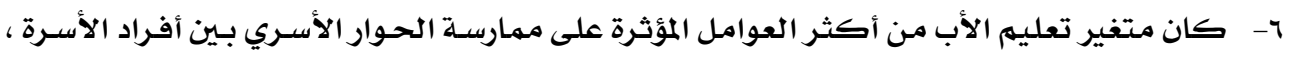

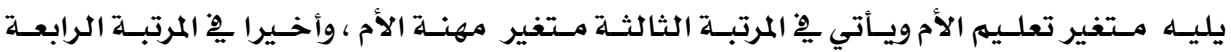
مهنة الأب . ملئه 


\title{
Abstract
}

\section{THE FAMILY DIALOGUE: ITS PRACTICES AND CONSTRAINTS INSIDE THE SAUDI FAMILIES AND ITS RELATIONS WITH SOME VARIABLES}

\author{
Dr. Muna Hamed Ibrahim Musa \\ Assistant Professor, \\ Department of housing and home \\ administration Ummal Qura University
}

\section{Introduction and research problem:}

Like many other Arab societies, it is noted that the current situation of Saudi society is affected by many global, regional, and local phenomena that cast shadows on all members of the community. The most obvious phenomenon is the gap among parents and their children in dialogue and varying concepts (Hesah Alwayli, 2009). The problem of the recent study is to recognize the extent of using the dialogue skills by the Saudi families and identifying the most important methods of talking inside the families for resolving their problems. In addition, the recent research is looking for the identifying the obstacles of that dialogue, the most commonly used skills of talk, monitoring some of factors affecting the family dialogue, spreading the culture of dialogue among the families' members as a real start for the individuals in their dealings and talking with each other.

\section{The research's objectives;}

1. Revealing the extent of using dialogue among the parents and their children inside the families of the research's sample.

2. Identifying some of the social, economic, and cultural variables and their effects on the use of dialogue among the families' members.

3. Identifying the most important obstacles of dialogue among the families' members.

\section{Search Results:}

1-There are significant differences among the means of the sample's responses towards the practice of dialogue with their children at the level 0.01 and the following variables (the parental educational qualifications, age, occupation, number of members, monthly income, children gender and school stages).

2-There are significant differences among the means of the sample's responses towards the obstacles of dialogue with their children at the 
level 0.01 and the following variables (the parental educational qualifications, age, occupation, number of members, monthly income, children gender and school stages).

3-There is a direct positive correlation among the domestic dialogue axis at the level 0.01 and the following variables (educational qualifications of fathers and mothers, profession of fathers and mothers, children ages, and school stages). There is a positive correlation among the axis of the domestic dialogue obstacles and the variable of the families' members at the level 0.01 .

4-There is an inverse correlation among the domestic dialogue axis at the level 0.01 with the variable of the families' members. In addition, there is an inverse correlation among the axis of the domestic dialogue obstacles and the following variables (educational qualifications of fathers and mothers, profession of fathers and mothers, children ages, and school stages).

5- There is no correlation among the domestic dialogue axis at the level 0.01 and the following variables (ages of fathers and mothers, monthly incomes, gender, and the orders of the children among their sisters and brothers). In addition, there is no correlation among the domestic dialogue obstacles axis at the level 0.01 and the following variables (ages of fathers and mothers, monthly incomes, gender, and the orders of the children among their sisters and brothers).

6-The educational qualifications of fathers are the most influential factors on practicing the dialogue among the family members, followed by the educational qualifications of mothers, then the mothers' professions of the mothers in the third rank, and finally the fathers' professions in the fourth rank. 


\title{
الهوار الأسري : مهمارساته ومعوقاته داخل الأسرة السعودية وعلاقته ببعض المتفيرات
}

\author{
إعداد \\ د. منححامد إبراهيمموسحمـ
}

الاقدهمة:

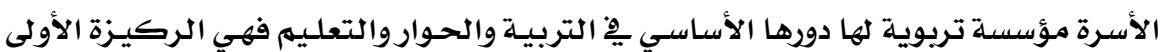

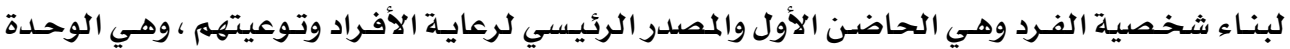

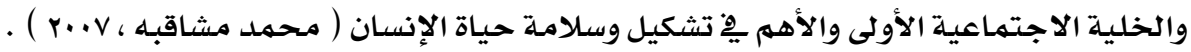

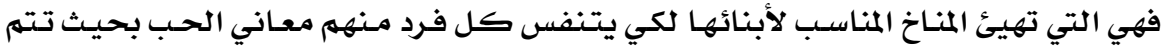

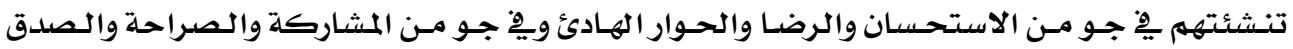

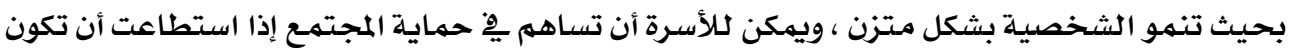

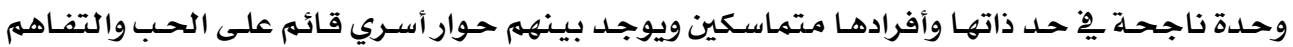
بحيث لا يشعر كل طرف منهم بأنه منعزل عن الطرف الآخر .

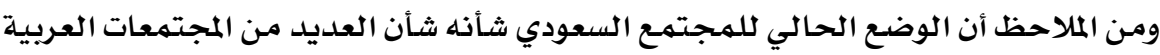

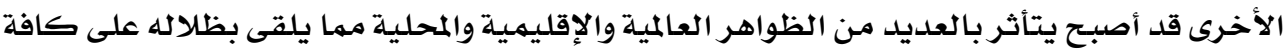

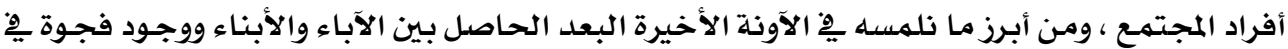

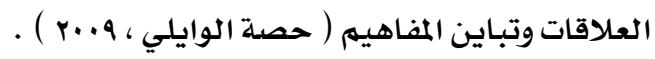

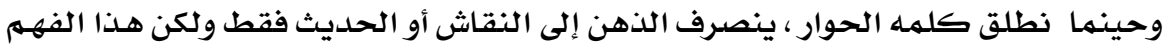

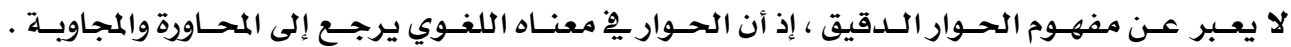

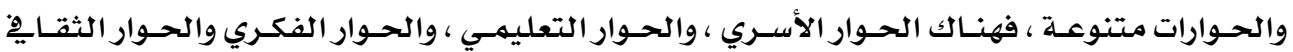

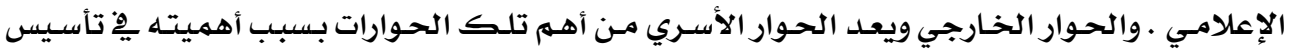

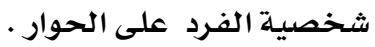

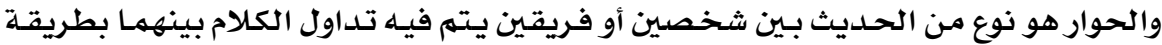

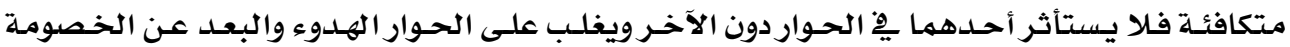

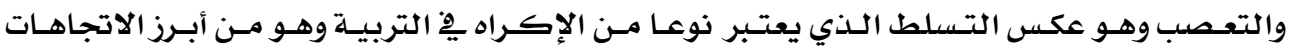

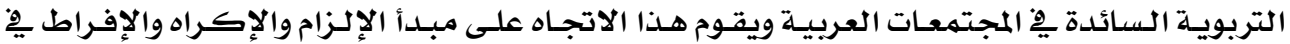

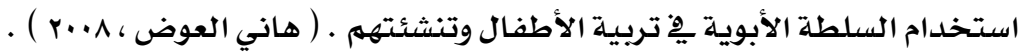
" أستاذ مسـاعد تخصص سكن وإدارة منزل جـامعة أم القرى 


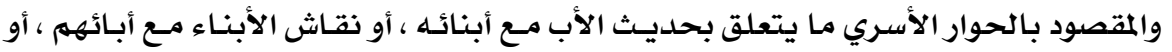

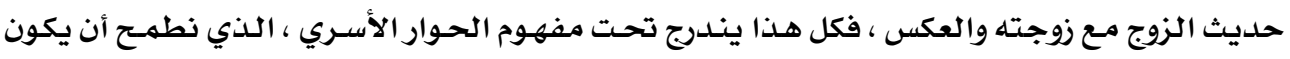

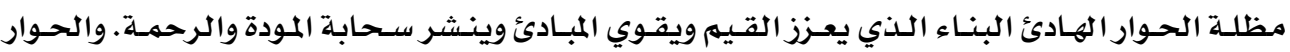

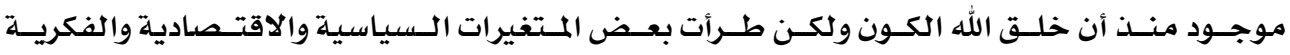

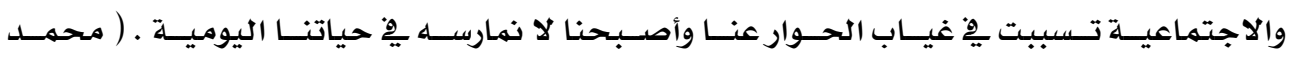

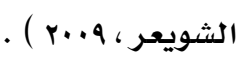

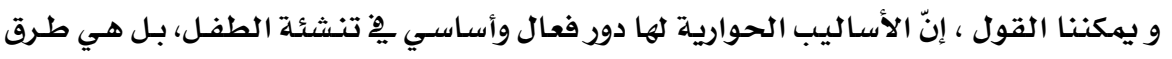

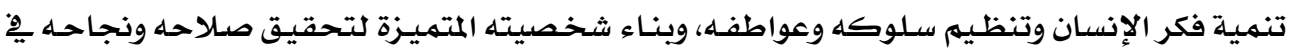

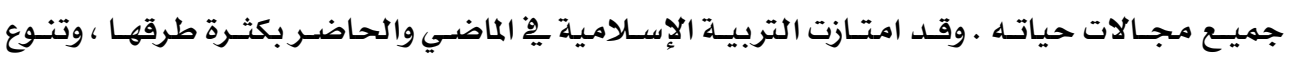

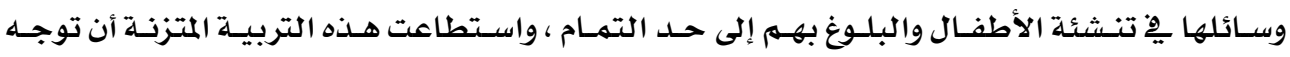

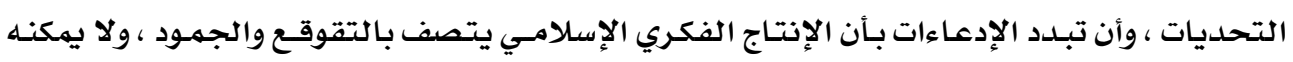

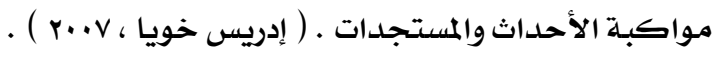

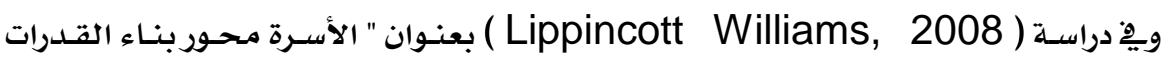

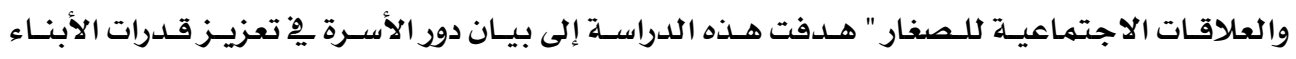

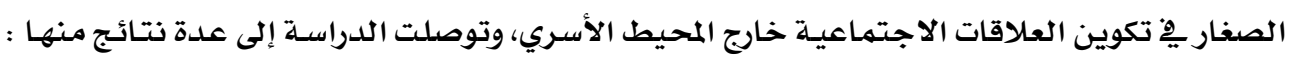

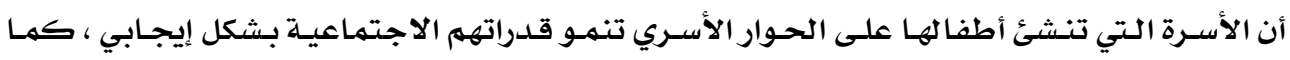

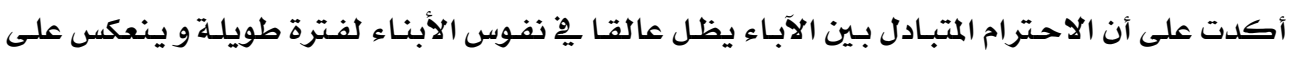

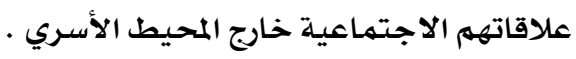

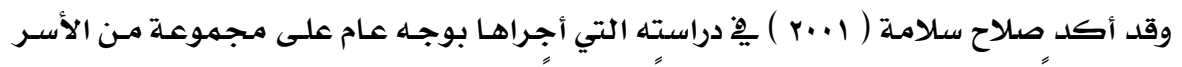

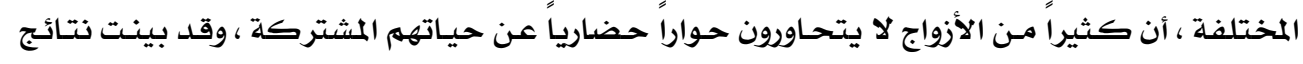

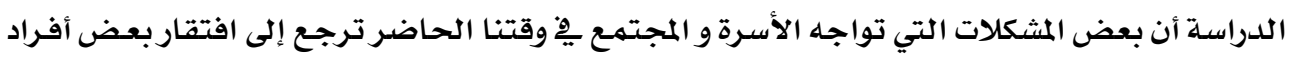

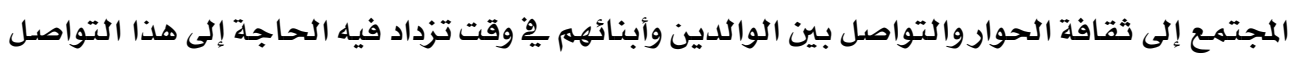

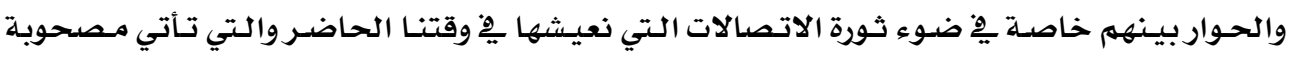

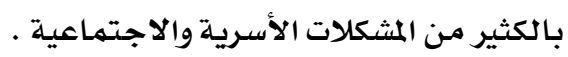
والحوار بين الزوجين هـو مفتـاح التفـاهم والانسجام وأن انعـدام الحـوار يعـني النـزاع الأسـري

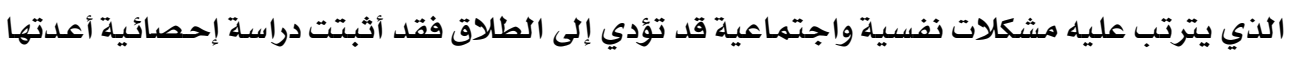

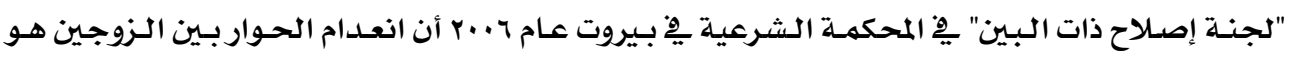

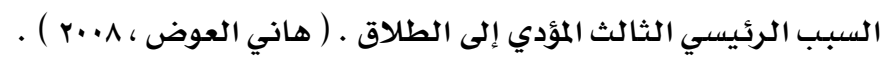

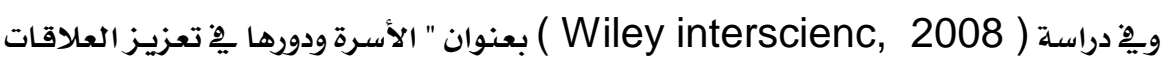

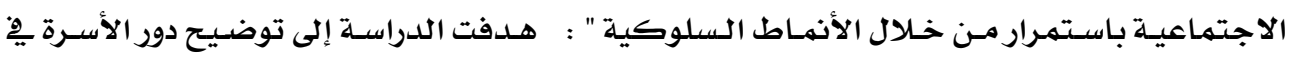

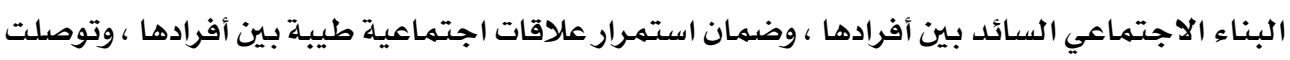

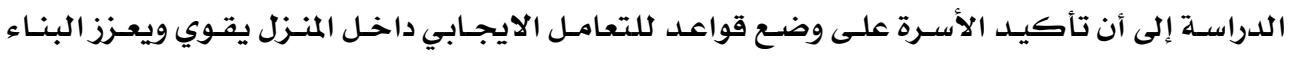




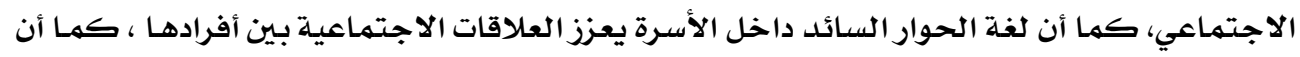

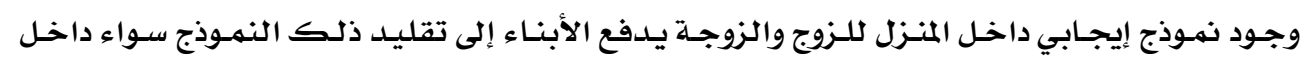
المنزل أو خارجه .

ولأهميـة الحوار الأسـري بين أفراد الأسـرة السعودية فقــ أجـري كرسي الأميرة صـيته بنـت

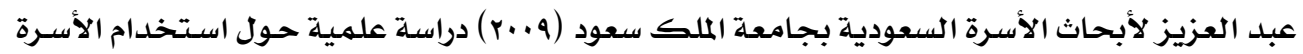

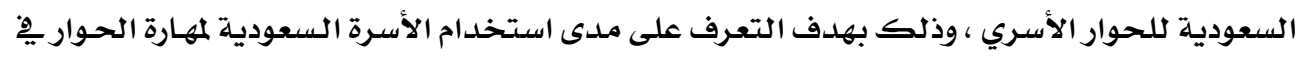

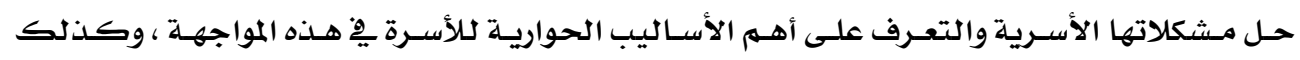

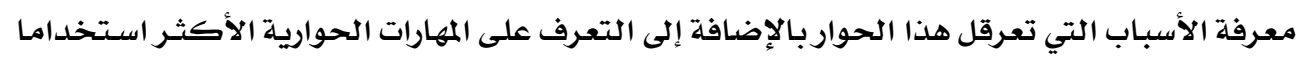

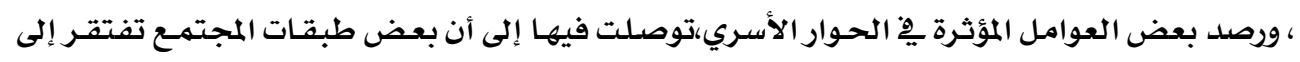

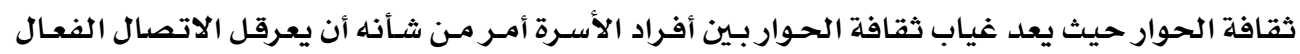

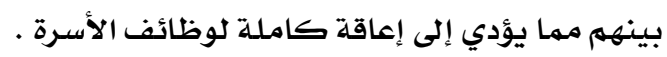

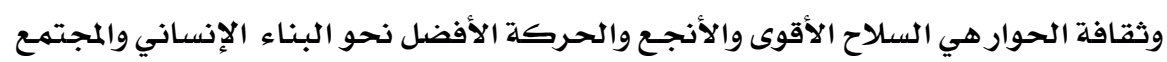

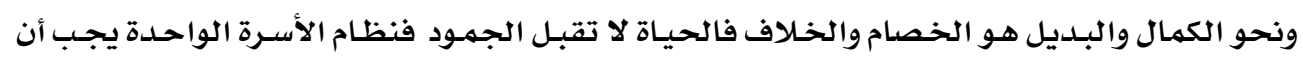

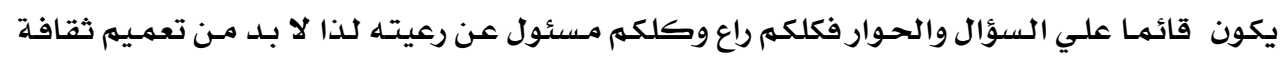

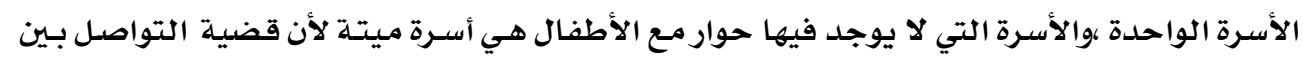

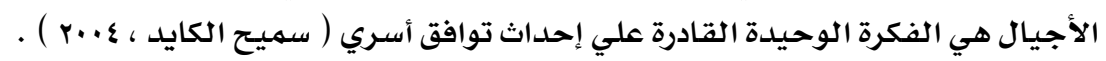

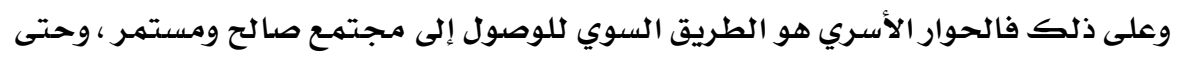

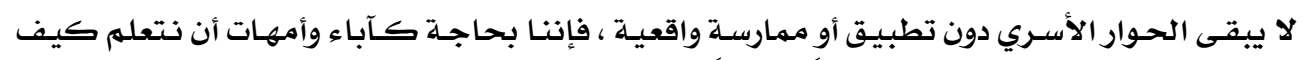

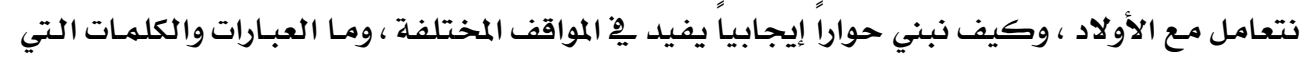

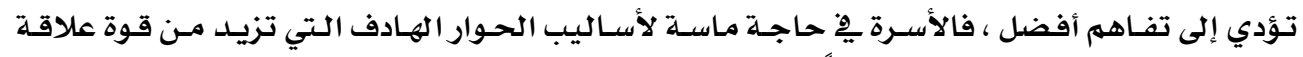

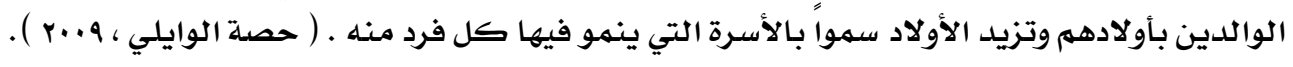

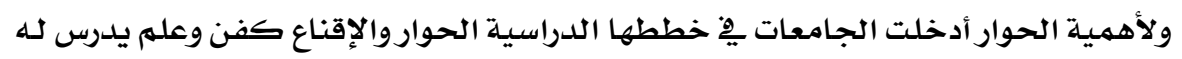

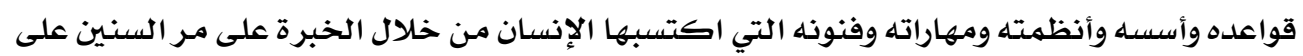

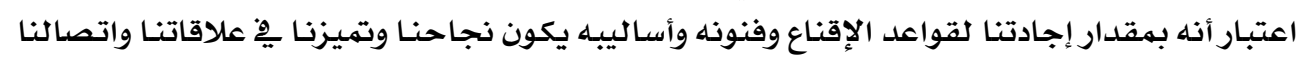

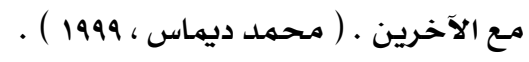

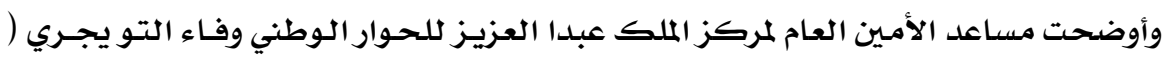

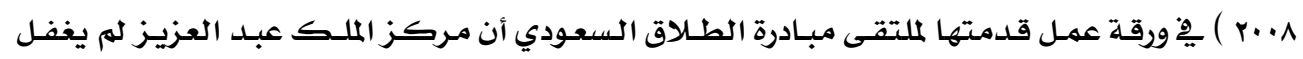

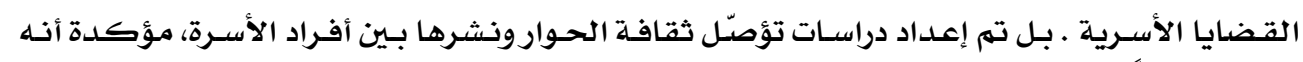

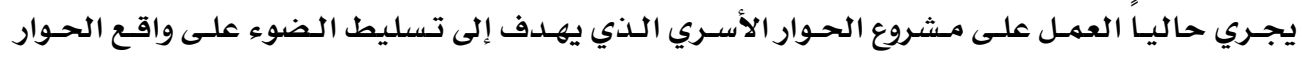

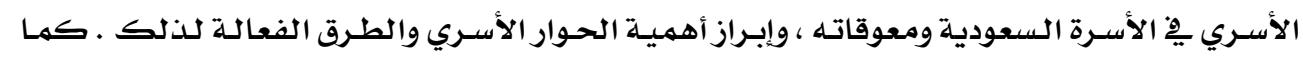

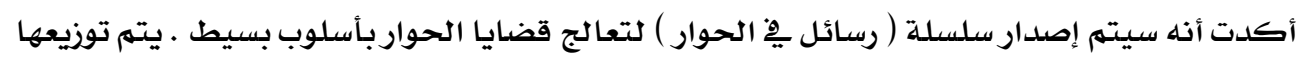

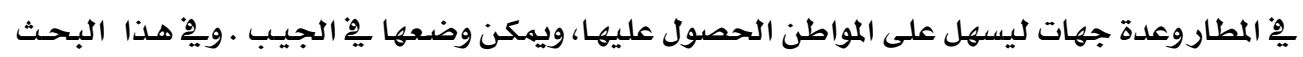


سيتم التركيز على معرفة مدىى ممارسة عينة من الأسـر السعودية للحوار الأسـري الهادف بين أفرادها

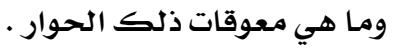

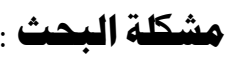

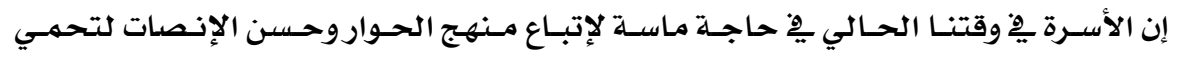

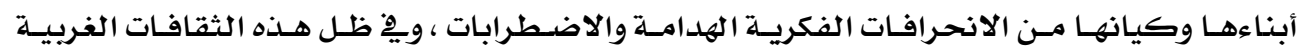

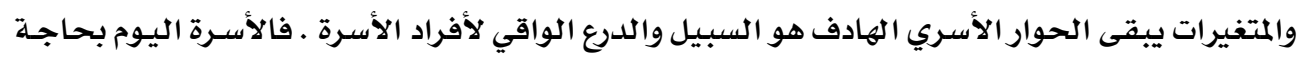

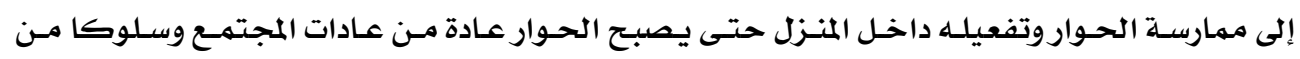

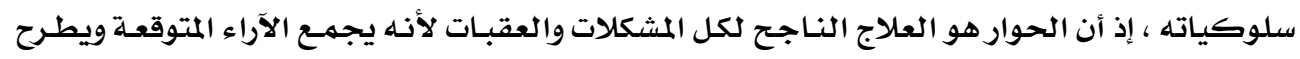

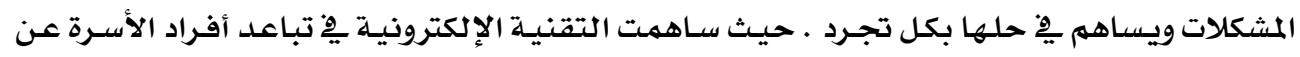

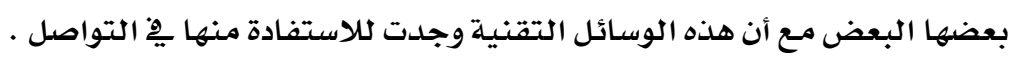
وعلى ضوء ما سبق تصاغ مشكلة البحث مِ التساؤلات الآتية :

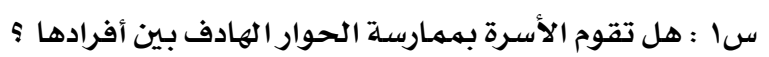

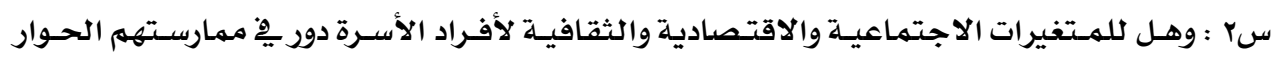
الأسري الهادف بينها وبين أبنائها ؟

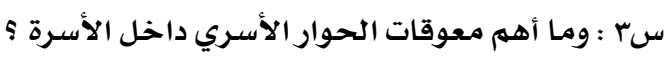

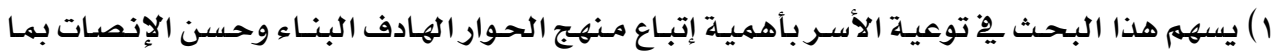

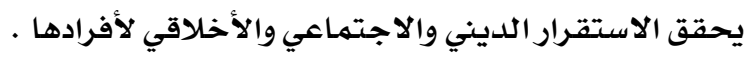

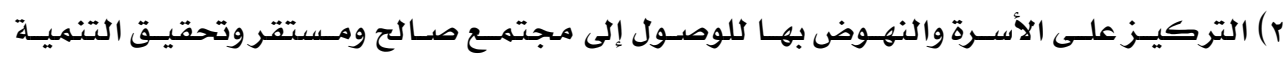

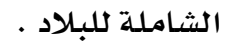

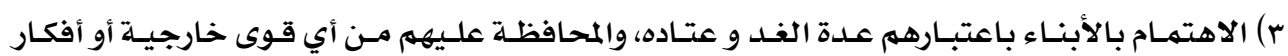

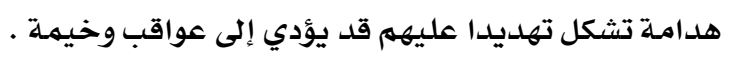

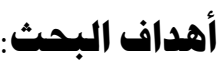

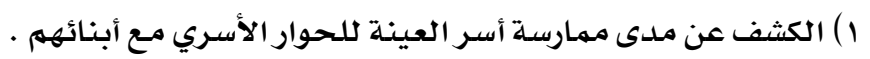

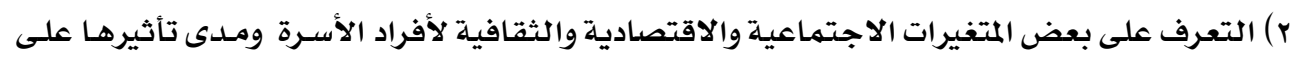

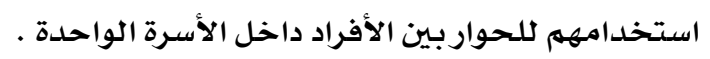

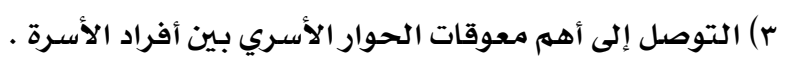

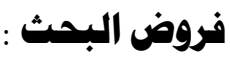

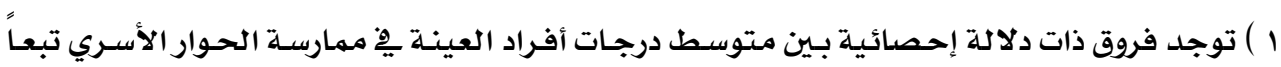

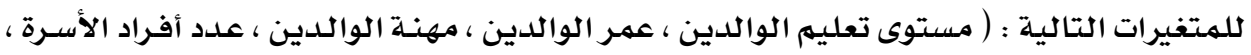

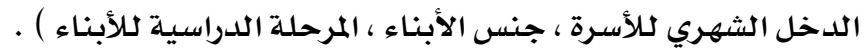


r ) توجد فروض ذات دلالة إحصائية بين متوسط درجات أفراد العينـة ِِِ معوقات الحسوار الأسـري تبعـا

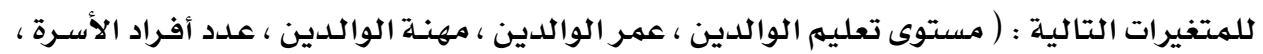

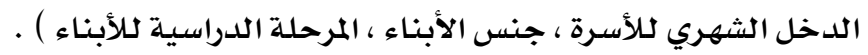

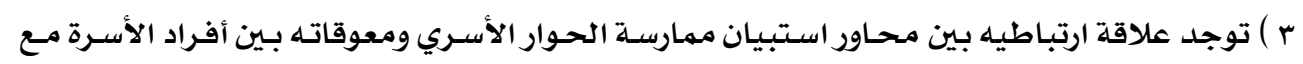

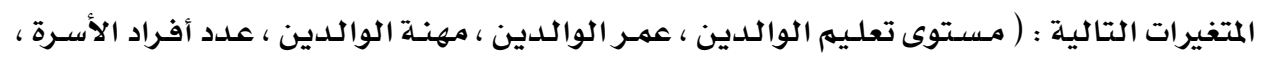

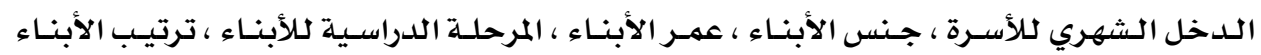

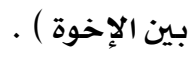

ع ) تختلف نسبة مشاركة العوامل المؤثرة على ممارسة الحوار الأسري بين أفراد الأسـرة .

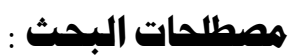

: DIALOGUE الحوار :

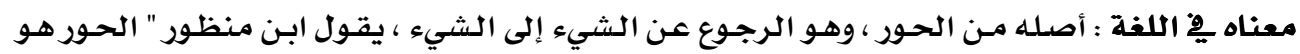

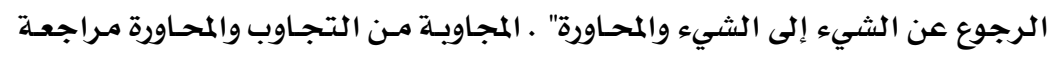

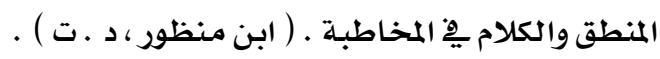

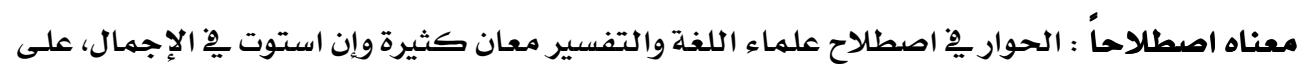

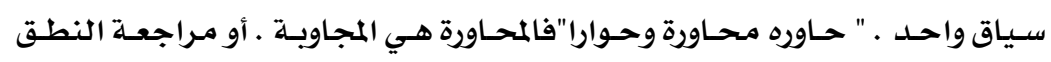

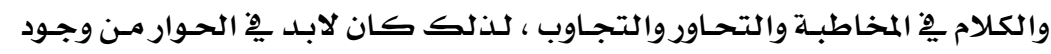

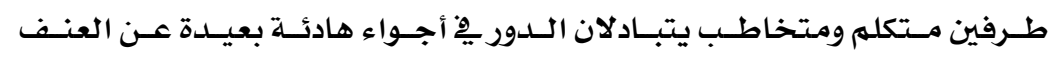

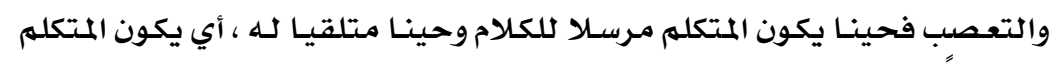

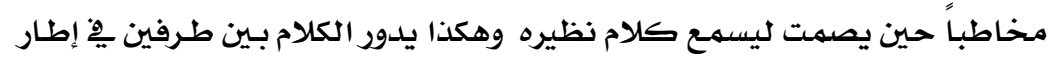

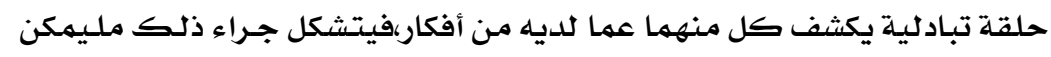

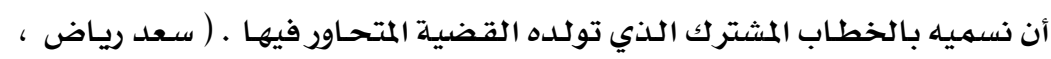
( r...v

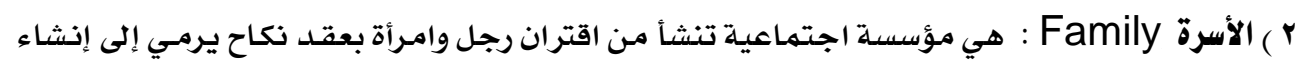

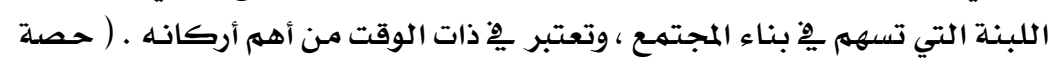

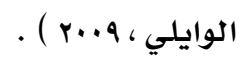

ץ ) الحوار الأسري DIALOGUE OF FAMILY : هو التفاعل بين أفراد الأسرة الواحدة عن طريق

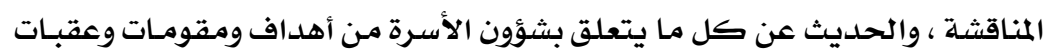

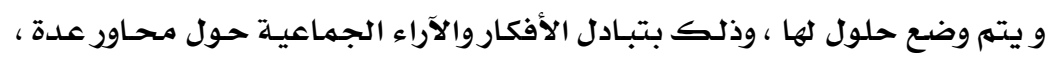

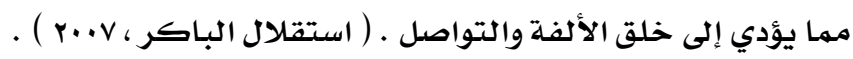




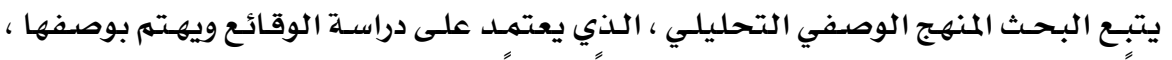

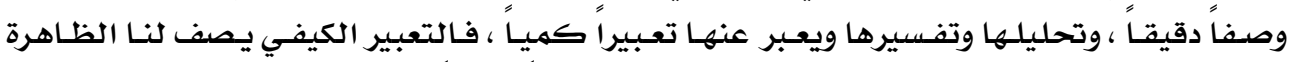

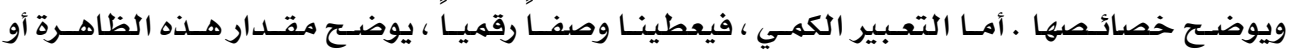

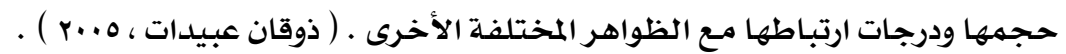
r

• الحدود المكانية : تم تطبيق الدراسة الميدانية بمحافظتي مكة المكرمة وجلدة .

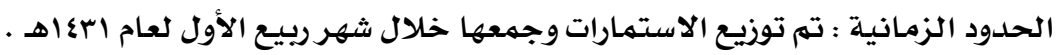

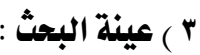

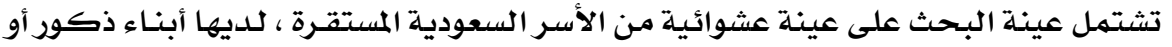

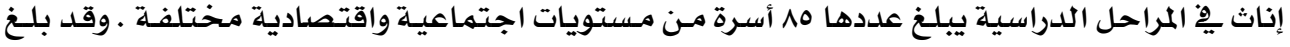

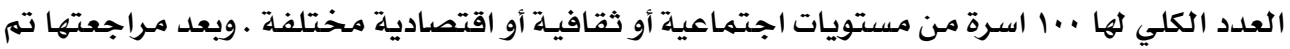

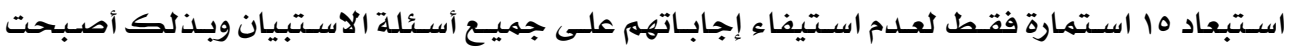

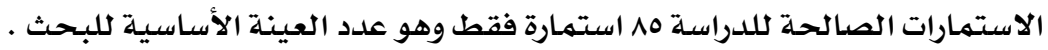
\&

لتحقيق أهداف هذه الدراسة تم تصميم استمارة استبيان اشتملت على مجموعة من المحاوروهي :

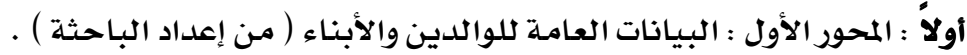

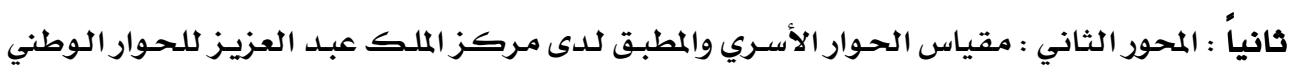

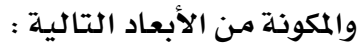

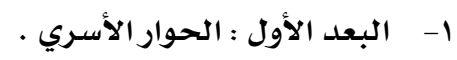

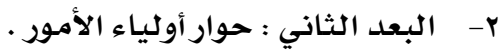

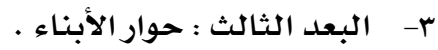

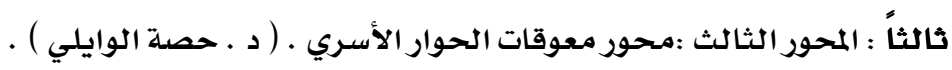
خطوات إعداد الاستبيياز : ولإعداد هذه الاستبيان تم إتباع الخطوات الآتية : ا - الإطلاع على الدراسات والبحوث السابقة .

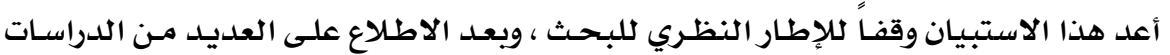

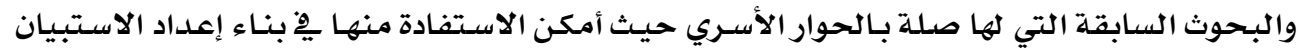
من حيث المحتوى والشكل . 


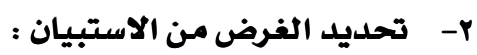 وضع هذا الاستبيان لتحقيق الأغراض الآتية :}

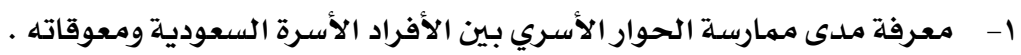

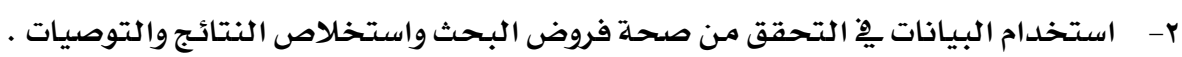
r - بناء الاستبيان: واشتمل على المحاور التالية

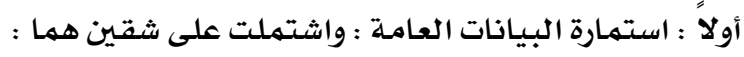
أ - - البيانات العامة للوالدين.

تم إعداد استمارة البيانات العامة للأسرة بهدف الحصول على بعض المعلومات التي تفيد بِ

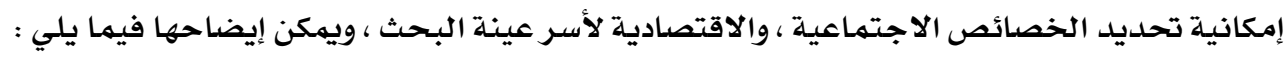

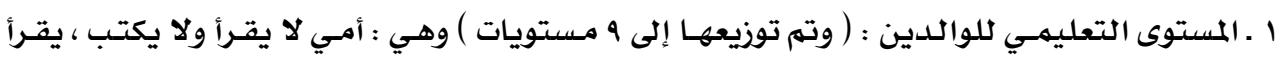

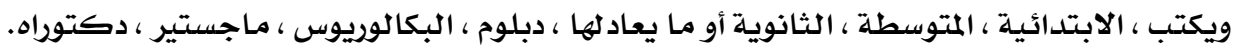

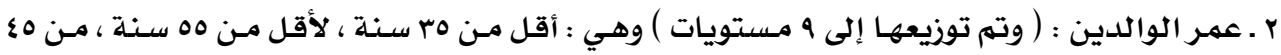

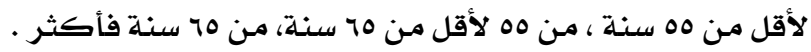

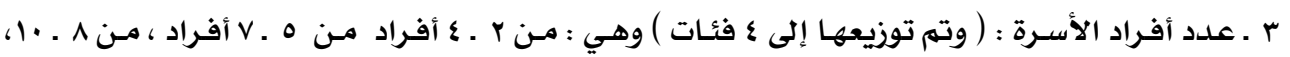

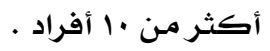

ع ـ مهنة الوالدين : ( وتم توزيعها إلى 0 فئات ) وهي : لا يعمل ، موظف حكومي ، قطاع خـاص ، أعمال ، مرال

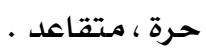

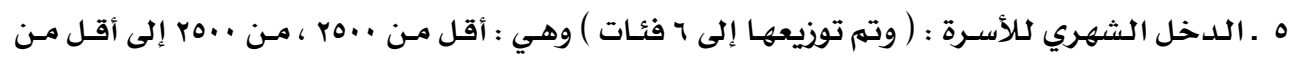

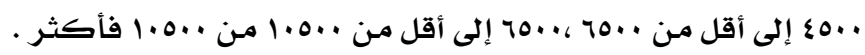

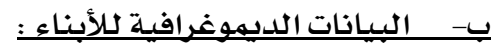

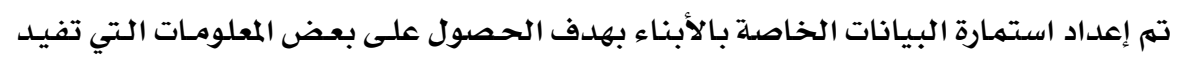

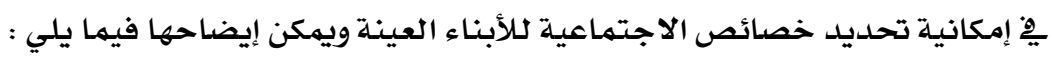

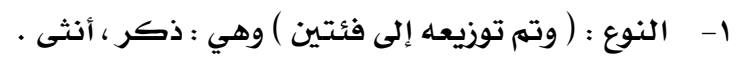

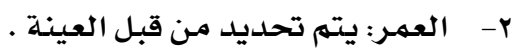

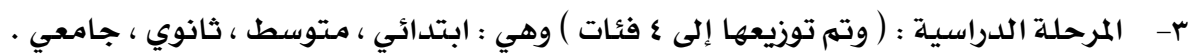

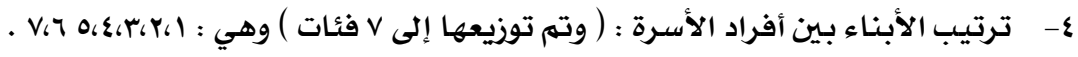
ثانياً: مقياس الحوار الأسري: ترتيب الابناء بلفراد الأين اشتمل المقياس على qه عبارة لقياس ممارسة الحوار الأسري بين أفراد الأسرة السعوديـة و قد تم توزيعها على ثلاثة أبعاد وهي : 


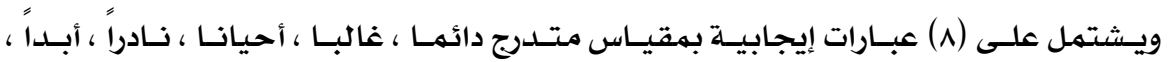

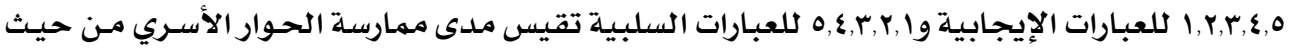

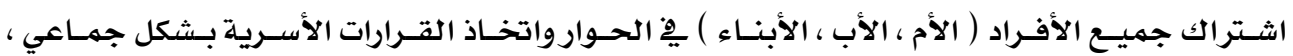

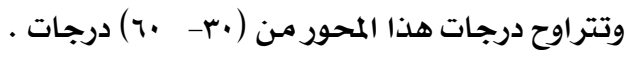

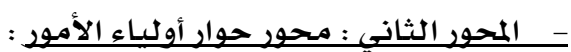

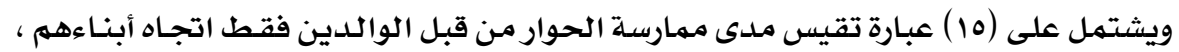

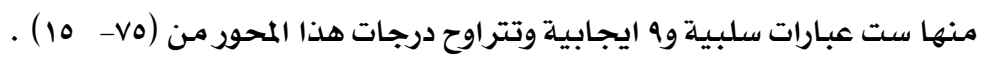
:

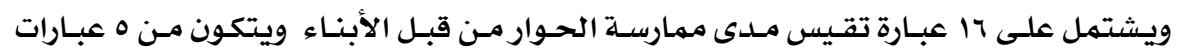

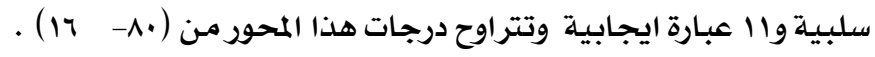
ثالثاً مقياس معوقات الحوار الأسري : ويشتمل على 10 عبارة سلبية تقيس أسباب فقدان الحوار الأسري بين أفراد الأسرة السعودية وتتراوح درجات هذا المحور من (10،V0) ). ع- الدراسة الاستطلاعية :

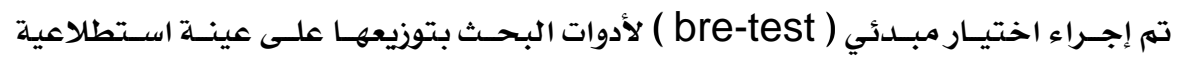

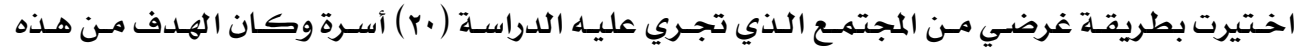

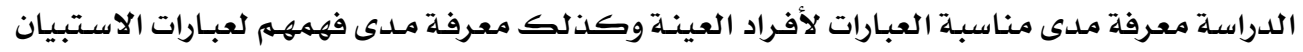
وذلك لاإلغاء الأسئلة غير الواضحة مدئة وتعديل صياغة بعضات لافراد العينة الأسئلة . ه- - مقنين الاستبيان : أ ـ : The validity :

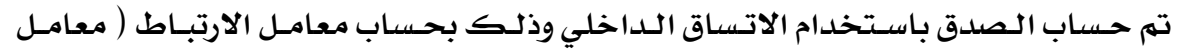

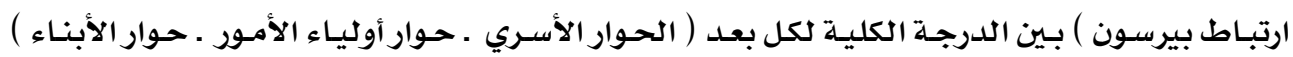

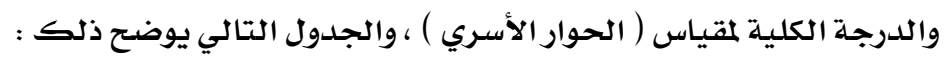
جدول ( 1 ) يبين قيم معاملات الارتباط بين درجة كل بعد ودرجة مقياس الحوار الأسري

\begin{tabular}{|c|c|c|}
\hline الدلالة & الارتباط & مقياس الحوار الأسري \\
\hline$\cdot, \cdot 1$ & •,A\&r & البعد الأول : الحوار الأسري . \\
\hline$\cdot, \cdot 1$ & $\cdot, 911$ & البعد الثاني : حوار أولياء الأمور . \\
\hline$\cdot, \cdot 1$ & •, Yo4 & البعد الثالث : حوار الأبناء \\
\hline
\end{tabular}




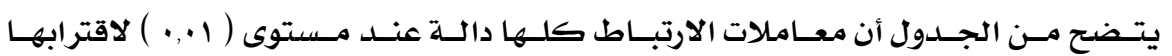
من الواحد الصحيح مما يدل على صدق وتجانس محاور الاستبيان . جدول ( r ) يبين قيم معاملات الارتباط بين درجة كل عبارة ودرجة مقياس معوقات الحوار الأسري

\begin{tabular}{|c|c|c|c|c|c|c|c|c|}
\hline الدلالة & الارتباط & $\hat{2}$ & الدلالة & الارتباط & A & الدلالة & الارتباط & ค \\
\hline$\cdot,+1$ & $\cdot, r+1$ & 11. & $\cdot, \cdot 1$ & $\cdot, \mathrm{V} \leqslant \Lambda$ & 7. & $\cdot, \cdot 1$ & $\cdot, \wedge \neg \vee$ & 1 \\
\hline$\cdot, \cdot 1$ & -,A^r & Ir. & $\cdot, \cdot 1$ & - VqV & $V_{-}$ & $\cdot, \cdot 1$ & - ,9YZ & $r$ \\
\hline$\cdot, \cdot 0$ & - I Y & ir. & $\cdot, \cdot 0$ & ו וד, & A. & $\cdot,+1$ & •, $\mathrm{V} \backslash \mathrm{A}$ & $r$ \\
\hline$\cdot,+1$ & - Y०Q & $1 \varepsilon$ & $\cdot, \cdot 1$ & $\cdot, 9 \leqslant 1$ & 9 & $\cdot, \cdot 0$ & •, 717 & $\varepsilon$ \\
\hline$\cdot, \cdot 0$ & - , y & 10. & $\cdot, \cdot 1$ & - , qrA & 1. & $\cdot, \cdot 1$ & $\cdot, \wedge \wedge \wedge$ & 0 \\
\hline
\end{tabular}

يتضح من الجدول أن معاملات الارتباط كلها دالة عند مستوى ( ا.,. ، ه .. • ) لاقترابها من

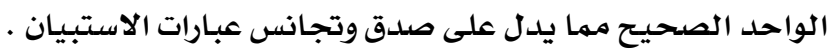
ب ـ بـات الاستبيان : The reliability جدول ( r ) يبين قيم معامل الثبات لأبعاد مقياس الحوار الأسري

\begin{tabular}{|c|c|c|c|}
\hline جيوتمان & التجزئة النصفية & معامل ألثا & المحـــــــــاور \\
\hline$\cdot, \wedge \leqslant 9$ & $\cdot, \wedge 9 \xi-\cdot, \wedge \cdot \wedge$ & $\cdot$, Arv & البعد الأول : الحوار الأسري \\
\hline$\cdot, \wedge \wedge 1$ & $\cdot, 91 \vee-\cdot, \wedge \leqslant \wedge$ & $\cdot, 9 \cdot 7$ & البعد الثاني : حوار أولياء الأمور \\
\hline$\cdot, 790$ & $\cdot$, var - •, yor & $\cdot, Y r V$ & البعد الثالث : حوار الأبناء \\
\hline$\cdot$, v & •, Arq- - vrr & $\cdot, \Lambda \cdot r$ & ثبات الاستبيان ككل \\
\hline
\end{tabular}

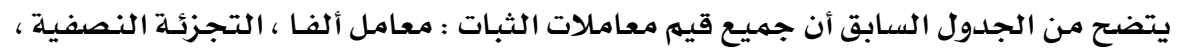

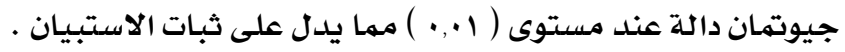

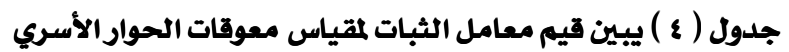

\begin{tabular}{|c|c|c|c|}
\hline جيوتمان & التجزئة النصفية & معامل الفا & مقياس المعوقات \\
\hline$\cdot$, А & $\cdot, 9 \cdot 1-\bullet, A Y I$ & $\cdot$, AA々 & ثبات الاستبيان ككل \\
\hline
\end{tabular}

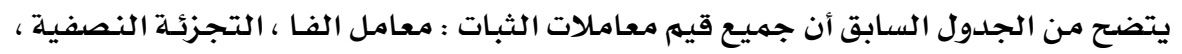

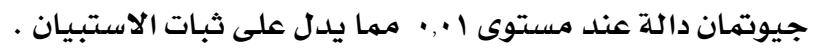

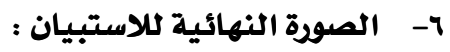

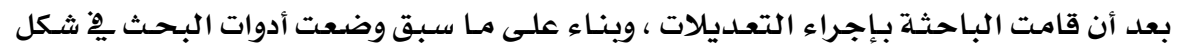

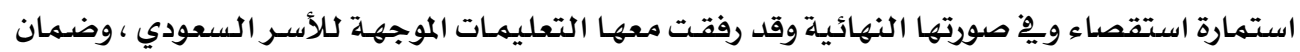


السـريلة التـامـة للبيـانـات وأنها لاسـتخدام لأغـراض البـحـث العلمـي فقط،حتى يكـون هنـاك مـصداقيـة

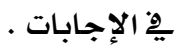

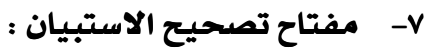

تحددت الإجابات على عبارات الاستبيان وقتاً لخمس اختيارات : إما الموافقة بكلمهة (دائماً) أو

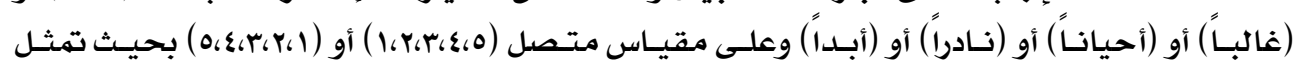
العبارات الايجابية بخمس درجات أو العبارات السلبيـة بلدرجـة واحدة .

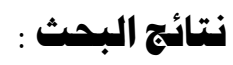

أولاً: وصف العينة

البيانات العامـة لنلأسـرة

1

جدول ( ه ) يبين توزيع الوالدين بعينة البحث تبعا لمتغير المستوى التعليمي

\begin{tabular}{|c|c|c|c|c|c|c|c|c|c|c|}
\hline \multicolumn{2}{|c|}{ مستوى تعليي } & وأمي لا يقرأ & ويكتب & الابتدادة ائية & الشتوسطة الشمة & الثانوية أو & دبلوم & البكالوريوس & ماجستير دكتوراه & المجموع \\
\hline \multirow{2}{*}{ الأب } & العلدد & $\xi$ & 0 & 9 & $\checkmark$ & 0 & 17 & rr & $\checkmark$ & 10 \\
\hline & النسبة./ & $\% \xi, \vee$ & $\% 0,9$ & $\% 1,7$ & $\%, \wedge, r$ & $\%, 0,9$ & $\%$ $\%, \wedge$ & $\% r v, 7$ & $\% \wedge, r$ & $\%$ \\
\hline \multirow{2}{*}{ الأم } & العلد & $\varepsilon$ & 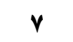 & 1. & 9 & $\wedge$ & ir & r & $\varepsilon$ & 10 \\
\hline & النسبة./ & $\% \boldsymbol{\varepsilon}, Y$ & $\% \wedge, r$ & $\% \Pi, \wedge$ & $\% 1 \cdot, 7$ & $\%$ \%, & $\% 1 \varepsilon, 1$ & $\%$ rq,o & $\%, \boldsymbol{\varepsilon}, \vee$ & $\%$ \\
\hline
\end{tabular}

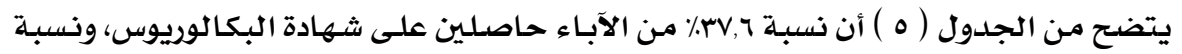

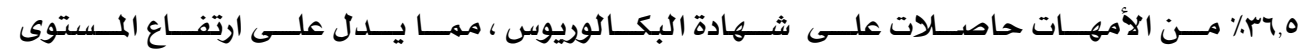
التعليهي للوالدين : ب عهـر الوالدبن

جدول ( ج) يبين توزيـ الوالدين بعينة البحث تبعا لمتغير العمر

\begin{tabular}{|c|c|c|c|c|}
\hline \multicolumn{2}{|c|}{ الأم } & \multicolumn{2}{|c|}{ الأب } & \multirow{2}{*}{ عمر الوالدين } \\
\hline النسبة.٪ & 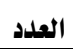 & النسبة./ & 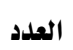 & \\
\hline$\%, r, r$ & M & $\% ॥, \Lambda$ & 17 & أقل من هب سنة \\
\hline$\%$ \% r r & ro & $\%$ ry,o & m & من ب سنة لأقل من 0؛ سنة \\
\hline$\%$ rr,o & r. & $\%$ rA, r & rร & من 0ح سنة لأقل من هه سنة \\
\hline$\% 1 \varepsilon, 1$ & ir & $\% 17,0$ & $1 \varepsilon$ & من ه سنة فأكثر \\
\hline$\%$ & 10 & $\%$ & 10 & المجموع \\
\hline
\end{tabular}




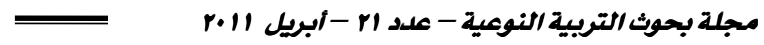

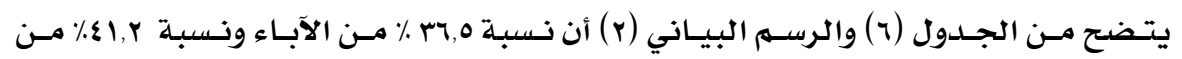

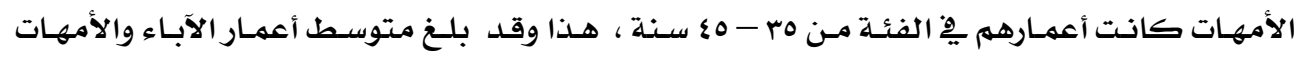
.

ب- علدد أفراد الأسيرة : ع

جدول ( v ) يبين توزيع أسر عينة البحث تبعاً لعدد أفرادها

\begin{tabular}{|c|c|c|}
\hline |النسبة./ & العدد & عدد أفراد الأسرة \\
\hline$\% r \cdot, \eta$ & rq & من ץ إلي ع أفراد \\
\hline$\% § 0,9$ & rq & من ه إلي v أفراد \\
\hline$\%$ rr,o & r. & من 1 أفراد فأكثر \\
\hline$\% 1 \cdots$ & 10 & المجموع \\
\hline
\end{tabular}

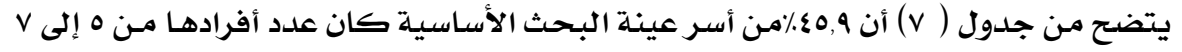

أفراد وقد بلـغ مـتوسط عدد أفرد اسـر عينـة البـحث (ه) أفراد . ؛ - مهنة الوالدبـن

جدول ( 1 ) يبين توزيع الوالدين بعينة البحث تبعا لمتغير المهنة

\begin{tabular}{|c|c|c|c|c|}
\hline \multicolumn{2}{|c|}{ الأم } & \multicolumn{2}{|c|}{ الأب } & \multirow{2}{*}{ مهنة الوالدين } \\
\hline النسبة./ & العدد & النسبة.| & العدد & \\
\hline$\% r v, 1$ & rr & $\% 10, r$ & ir & لا يعمل \\
\hline$\%$ \&,$\xi$ & mq & $\%$ & r६ & موظف حكومي \\
\hline$\% 1 v, 7$ & 10 & $\% \nvdash \varepsilon, Y$ & rI & قطاع خاص \\
\hline$\%$ Ir,q & 11 & $\%$ & iv & أعمال حرة \\
\hline$\% 1 \cdots$ & 10 & $\% 1 \cdots$ & 10 & المججموع \\
\hline
\end{tabular}

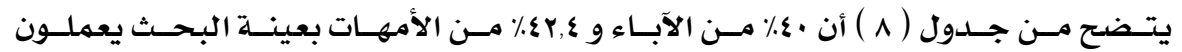

بالوظائف الحكوميـة .

ه- ـ الدخل الشهـري لكلأسـرة : 
الحوار الأسري : ممارساته ومعوقاته داخل الأسرة السعودية وعلاقته بيعض المتفيرات

جدول ( 9 ) يبين توزيع أسر عينة البحث وفقا لفئات الدخل المختلفة

\begin{tabular}{|c|c|c|}
\hline النسبة. & 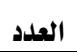 & الدخل الشهري للأسرة \\
\hline$\%, \Lambda, r$ & $\checkmark$ & أقل من •.0r ريال \\
\hline$\% 1 \xi, 1$ & ir & 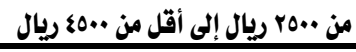 \\
\hline$\% 10, r$ & ir & من ••0ء ريال إلى أقل من •.010 ريال \\
\hline$\% 1 \vee, 7$ & 10 & من ••10 ريال إلى أقل من ••10 ريال \\
\hline$\%$ ro, 9 & rr & من ••1 ريال إلى أقل من ••0.1 ريال \\
\hline$\% 1 \Lambda, \Lambda$ & 17 & من .•0. اريال فأكثر \\
\hline$\%$ & 10 & المجموع \\
\hline
\end{tabular}

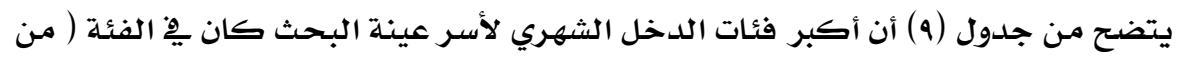

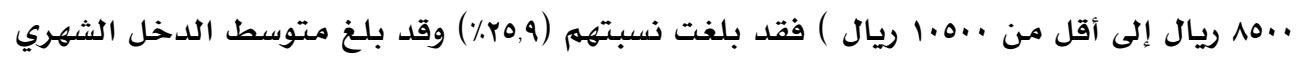

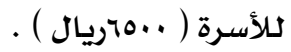

البيانات الديموغرافية لأبناء :

- الجنس

جدول ( ـ ابين توزيع الأبناء بعينة البحث تبعا لمتغير الجنس

\begin{tabular}{|c|c|c|}
\hline النسبة./ & المدد & الجنس \\
\hline$\%$ \% r , & rq & ذكر \\
\hline$\% ० v, Y$ & $\leqslant 9$ & أثثى \\
\hline$\%$ & 10 & المجموع \\
\hline
\end{tabular}

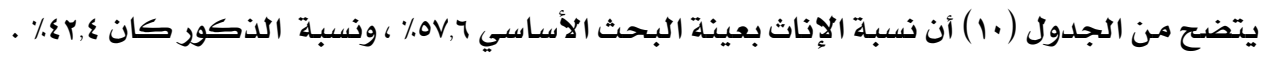
: ب عمر الأبناء

جدول (11) يبين توزيع الأبناء بعينة البحث تبعا لمتغير العمر

\begin{tabular}{|c|c|c|}
\hline النسبة. & العدد & العمر \\
\hline$\% 17,0$ & $\varepsilon$ & من Y سنوات إلي II سنة \\
\hline$\% \ll \varepsilon, Y$ & ra & من rا سنه إلي 17 سنة \\
\hline$\% \% \wedge, \wedge$ & $r$ & من VI سنه إلي اY سنة \\
\hline$\%$ & 10 & المجموع \\
\hline
\end{tabular}

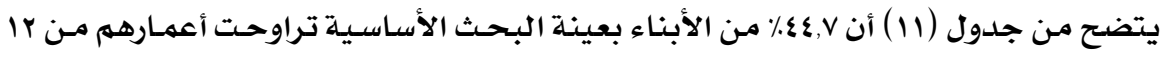

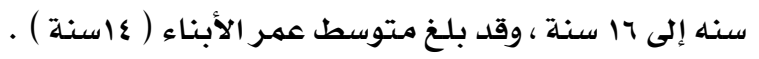


جدول ( r r) يبين توزيع الأبناء بعينة البحث تبعاً لمتغير المرحلة الدراسية

\begin{tabular}{|c|c|c|}
\hline النسبة.٪ & العدد & المرحلة اللدراسية \\
\hline$\% 17,0$ & 1\& & ابتدائي \\
\hline$\% r v, 7$ & rr & متوسط \\
\hline$\%$ \%r,q & $r \Lambda$ & ثانوي \\
\hline$\%$ Ir,q & 11 & جامعي \\
\hline$\%$ & 10 & المجموع \\
\hline
\end{tabular}

يتضح من جدول ( r r ) أن rV,V من الأبناء بالمرحلة المتوسطة .

ع- تـرتيـب الأبنـاء بـين الإخوة :

جدول (ri ) يبين توزيع الأبناء بعينة البحث تبعاً لترتيبهم بين أخوتهم

\begin{tabular}{|c|c|c|}
\hline | النسبة. & العلدد & ترتيب الأبناء بين الإخوة \\
\hline$\% \wedge, r$ & $v$ & الأول \\
\hline$\%, r, r$ & M & 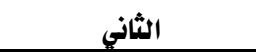 \\
\hline$\%$ & rr & 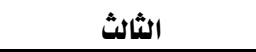 \\
\hline$\%$ Y,$\bigvee$ & ri & 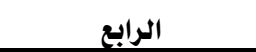 \\
\hline$\% \mid \varepsilon, 1$ & ir & 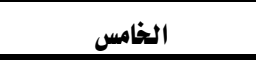 \\
\hline$\%$ & 10 اللهأسرةثلله & المجموع \\
\hline
\end{tabular}

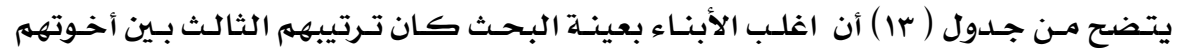

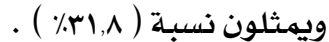

ثانياً :التحقق من صحة الثروض

$$
\text { الفرض الأول : }
$$

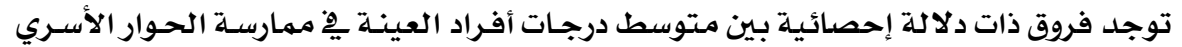

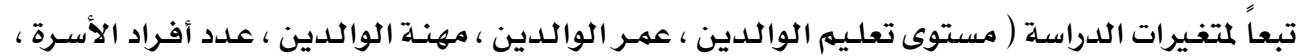
الدخل الشهري للأسرة ، جنس الأبناء ، المرحلة الدراسية لكلأبناء ) .

وللتحقق من هذا الفرض تم حسـاب تحليل التبـاين لـدرجات أفراد العينـة يْ مهارسسة الحـوار

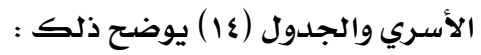


الحوار الأسري : ممارساته ومعوقاته داخل الأسرة السعودية وعلاقته ببعض المتغيرات

جدول (ع ) تحليل التباين لدرجات أفراد العينة يُ محورالحوار الأسري تبعا لمتغير تعليم الأب

\begin{tabular}{|c|c|c|c|c|c|}
\hline الدلالة & قيمة (ف) & درجات الحرية & متوسط المربعات & مجموع المربعات & مستوى تعليم الأب \\
\hline \multirow{3}{*}{ ו•,• دال } & \multirow{2}{*}{01,941} & $r$ & 1.qr.r, rss & MIAT.\&, TAV & بين المجموعات \\
\hline & & $A r$ & $1100, \cdot v \xi$ & $10 \mathrm{r117}, \cdot 70$ & داخل المجموعات \\
\hline & & $\Lambda \varepsilon$ & & rr.Vr., vor & المجموع \\
\hline
\end{tabular}

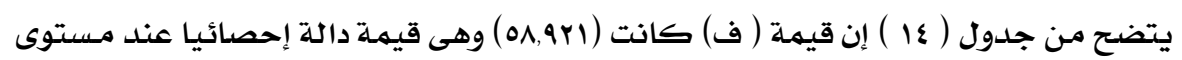

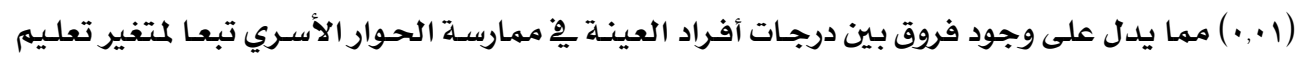

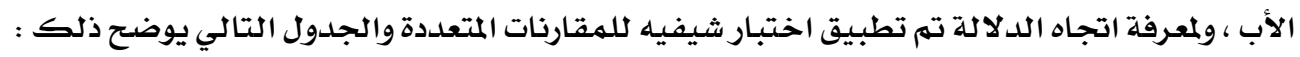
جدول ( 10 ) ) اختبار شيفيه للمقارنات المتعددة

\begin{tabular}{|c|c|c|c|}
\hline 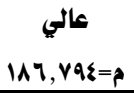 & $\begin{array}{c}\text { متوسط } \\
90,1 \leqslant Y=\text { م }\end{array}$ & منخفض & مستوى تعليه الأب \\
\hline & & - & منخفض \\
\hline & - & $* * \varepsilon r, r \cdot q$ & متوسط \\
\hline - & $* \$ 91,70 \mathrm{r}$ & $* *|r \varepsilon, q 7|$ & عالي \\
\hline
\end{tabular}

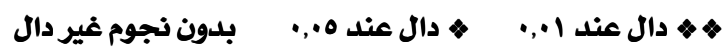

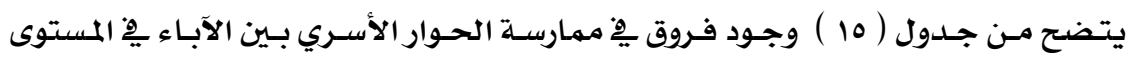

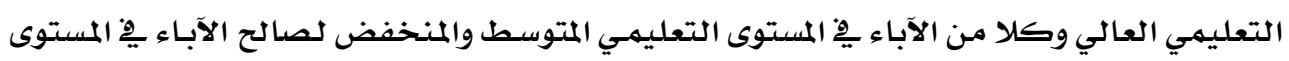

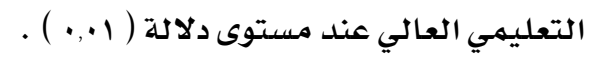

جدول (17 ) تحليل التباين لدرجات أفراد العينة فِ ممارسة الحوار الأسري تبعا لمتغير تعليم الأم

\begin{tabular}{|c|c|c|c|c|c|}
\hline الدلالة & قيمة (ف) & درجات الحرية & متوسط المربعات & مجموع المربعات & مستوى تعليم الأم \\
\hline \multirow{3}{*}{ 1.,• دال } & \multirow{2}{*}{ Or, TAY } & $r$ & $1 \cdot 141 \cdot 1 \cdot 1 \cdot 7$ & rIrry.,rII & بين المجموعات \\
\hline & & Ar & MAAE,ITY & $10 \leqslant \leqslant 9 \Lambda, \wedge \cdot \cdot$ & داخل المجموعات \\
\hline & & $\wedge \varepsilon$ & & rrinOa, +11 & المجموع \\
\hline
\end{tabular}

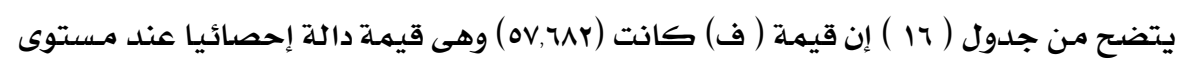

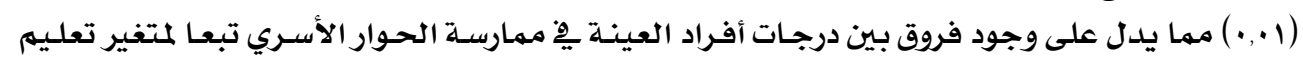

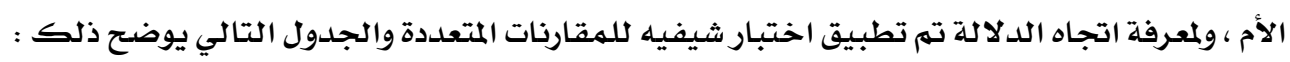


جدول ( ) ) اختبار شيفيه للمقارنات المتعددة

\begin{tabular}{|c|c|c|c|}
\hline 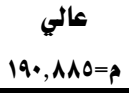 & 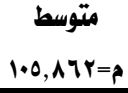 & $\begin{array}{c}\text { منخفض } \\
\text { Or, }, \wedge O V=\text { P }\end{array}$ & مستوى تعليي الأم \\
\hline & & - & منخفض \\
\hline & - & $* * 0 Y, \cdots \varepsilon$ & متوسط \\
\hline - & $* * \wedge 0, \cdot r r$ & $* * \mid r V, \cdot Y \Lambda$ & عالي \\
\hline
\end{tabular}

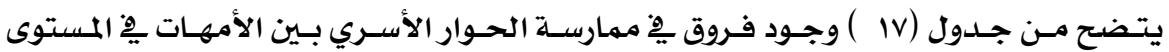

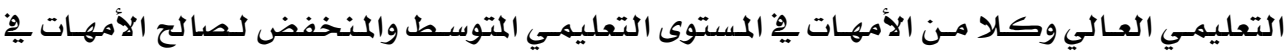

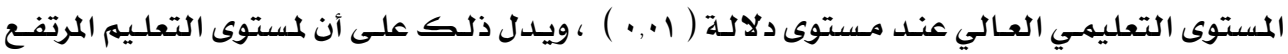

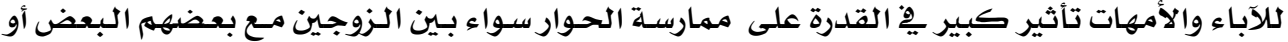

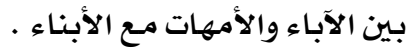

جدول ( 11 ) تحليل التباين لدرجات أفراد العينة فِّ ممارسة الحوار الأسري تبعا لمتغير عمر الأب

\begin{tabular}{|c|c|c|c|c|c|}
\hline اللالالة & قيمة (ف) & درجات الحرية & متوسط المربعات & مجموع المربعات & عمر الأب \\
\hline \multirow{3}{*}{ 1•,• دال } & \multirow{2}{*}{$\llbracket \xi, \Gamma \wedge \wedge$} & $r$ & rrarr,.07 & r1A919,179 & بين المجموعات \\
\hline & & $\wedge 1$ & 17\&r,arr & $\mid$ IrIII,AYI & داخل المجموعات \\
\hline & & $\wedge \varepsilon$ & & ror.A•, qAr & المجموع \\
\hline
\end{tabular}

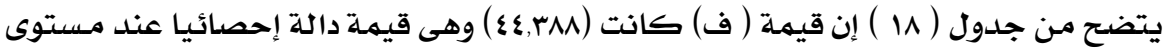

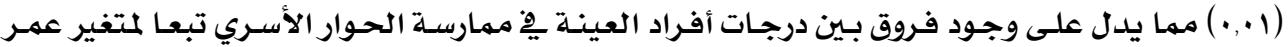

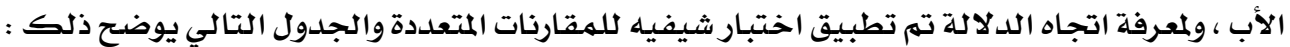
جدول ( 19 ) اختبار شيفيه للمقارنات المتعددة

\begin{tabular}{|c|c|c|c|c|}
\hline $\begin{array}{l}\text { من } 00 \text { سنة فأكثر } \\
\text { VY, }\end{array}$ & من سنة سنة لأقل من & من سنة سنة لأقل من Oک & 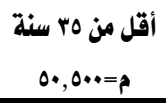 & عمر الأب \\
\hline & & & - & أقل من ro سنة \\
\hline & & - & $* * \wedge \vee, r T \wedge$ & من ro سنة لأقل من 0؟ سنة \\
\hline & - & $* * \pi 1, v \leq \varepsilon$ & $*+1 \leqslant 9, \wedge r$ & 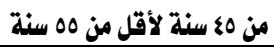 \\
\hline- & $*$ \& rV,rтq & $* * 70,7 Y \varepsilon$ & $*$ \&I,VIE & من 00 سنة فأكثر \\
\hline
\end{tabular}

يتضح من جدول ( 19 ) وجـود فروق مِِ ممارسـة الحـوار الأسـري بـين الآبـاء ذوى السن مـن 0؛

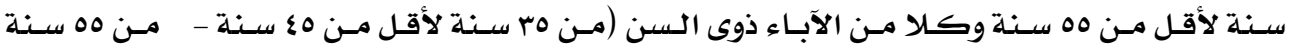

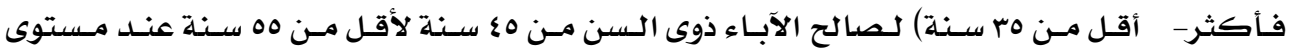
دلالة (1., (. ) ). 
الحوار الأسري : ممارساته ومعوقاته داخل الأسرة السعودية وولاقته بيعض المتغيرات

جدول ( • ) ) تحليل التباين لدرجات أفراد العينة فِ ممارسة الحوار الأسري تبعا لمتغير عمر الأم

\begin{tabular}{|c|c|c|c|c|c|}
\hline الدلالة & قيمة (ف) & درجات الحرية & متوسط المربعات & مجموع المربعات & عمر الأم \\
\hline \multirow{3}{*}{ 1•,• دال } & \multirow{2}{*}{$7 \cdot, r \wedge 9$} & $r$ & $77 \wedge 0 \xi, r 1$. & Y..07r,वYq & بين المجموعات \\
\hline & & A1 & $11 \cdot v, \cdot 00$ & 197YI, \&Y) & داخل المجموعات \\
\hline & & $\Lambda \varepsilon$ & & rq.rT\&,\&.• & المجموع \\
\hline
\end{tabular}

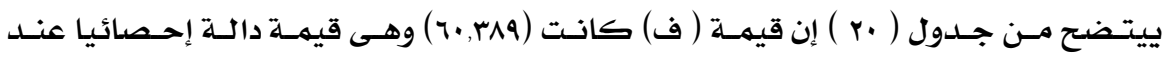

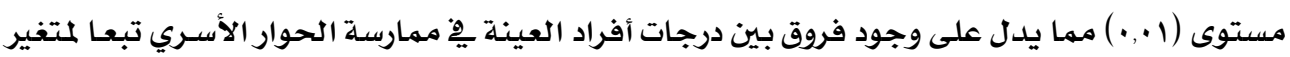

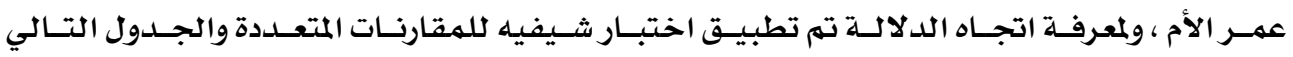
يوضح ذلك :

جدول ( ) ا r ) اختبار شيفيه للمقارنات المتعددة

\begin{tabular}{|c|c|c|c|c|}
\hline من مه سنة فأكثر & 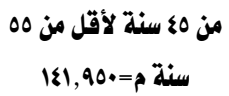 & 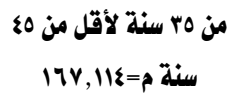 & 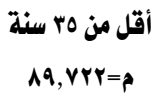 & عمر الأم \\
\hline & & & - & أقل من ro سنة \\
\hline & & - & $* *$ vvrrar & من هO سنة لأقل من ه؟ سنة \\
\hline & - & $\&$ ro,17£ & $* *$ Or,YrV & من 0خ سنة لأقل من ه سنة \\
\hline- & $* * q r, v *$ & $* * 111,17 \varepsilon$ & $* * \leqslant 1, \varepsilon V Y$ & من $ه 0$ سنة فأكثر \\
\hline
\end{tabular}

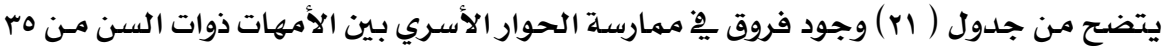

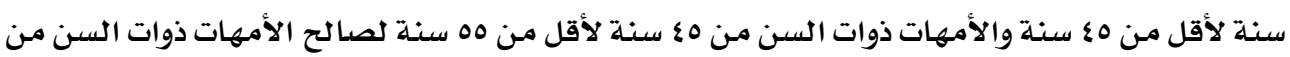

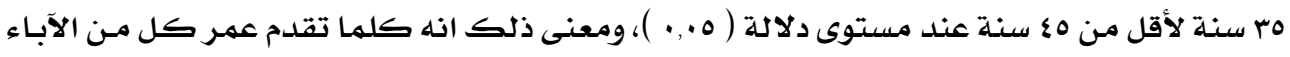

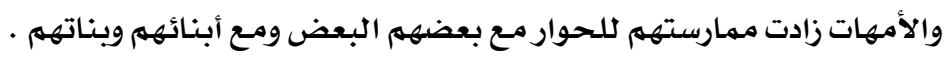

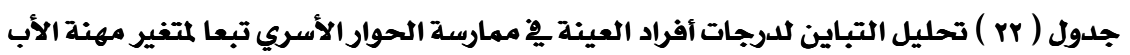

\begin{tabular}{|c|c|c|c|c|c|}
\hline الدلالة & قيمة (ف) & درجات الحرية & متوسط المربعات & مجموع المربعات & مهنة الأب \\
\hline \multirow{3}{*}{ ו•,• دال } & \multirow{2}{*}{$\Delta\}, Y Y \wedge$} & $r$ & VY.PV, ITI & $r|\Psi \cdot r|,\{A \varepsilon$ & بيز المجموعات \\
\hline & & $\wedge 1$ & ITIE,OYE & $1.7 \& \vee 7, \leqslant \vee 0$ & داخل المجموعات \\
\hline & & $\Lambda \varepsilon$ & & rrrßqY, १०१ & المجموع \\
\hline
\end{tabular}

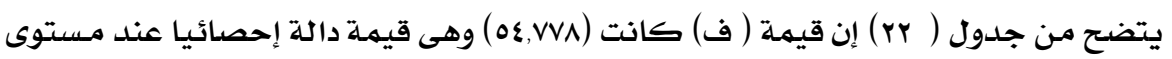

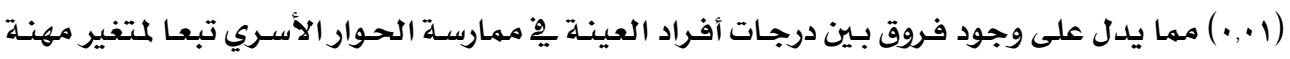

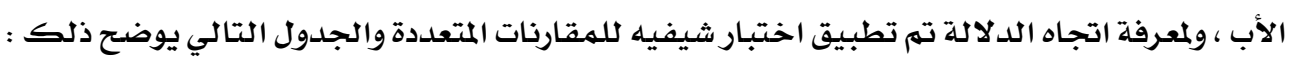


جدول ( rr ) ) اختبار شيفيه للمقارنات المتعددة

\begin{tabular}{|c|c|c|c|c|}
\hline $\begin{array}{l}\text { أعمال حرة = } \\
\text { =1 IVY, }\end{array}$ & موظف قطاع خاص & 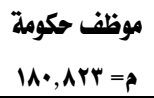 & $\begin{array}{c}\text { لا يعمل } \\
17 r, r \cdot v\end{array}$ & مهنة الأب \\
\hline & & & - & لا يعمل \\
\hline & & - & $\$ 1 V, 010$ & موظف حكومة \\
\hline & - & $* * 9 \vee, 911$ & $* * \wedge \cdot, \varepsilon \cdot r$ & موظف قطاع خاص \\
\hline- & $* *$ MI,VYN & $* * \mid r 9,7 \varepsilon V$ & $* *|| r,|r|$ & أعمال حرة \\
\hline
\end{tabular}

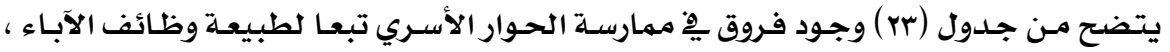

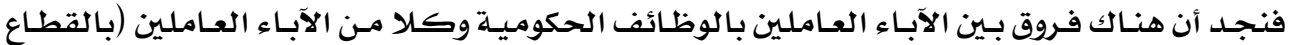

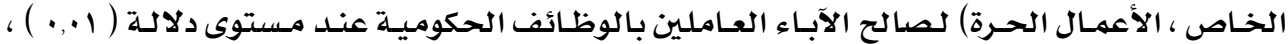

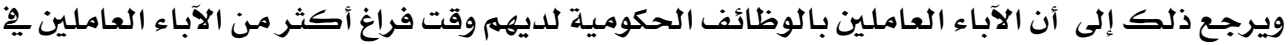

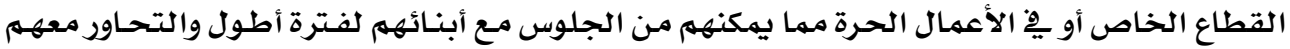
مِّ شؤون حياتهم .

جدول ( ع ) تحليل التباين لدرجات أفراد العينة فِ ممارسة الحوار الأسري تبعا لمتغير مهنة الأم

\begin{tabular}{|c|c|c|c|c|c|}
\hline الدلالة & قيمة (ف) & درجات الحرية & متوسط المربعات & مجموع المربعات & مهنة الأم \\
\hline \multirow{3}{*}{ ו•,• دال } & \multirow{2}{*}{ Tr,sor } & $r$ & rrrAl, , r & 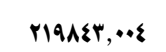 & بين المجموعات \\
\hline & & $\wedge 1$ & $\| 10 \xi, A \mid r$ & arora,Ala & داخل المجموعات \\
\hline & & $\wedge \varepsilon$ & & TIFrat,Art & المجموع \\
\hline
\end{tabular}

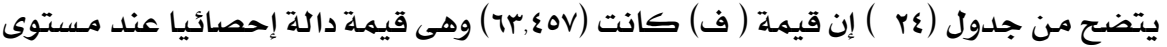

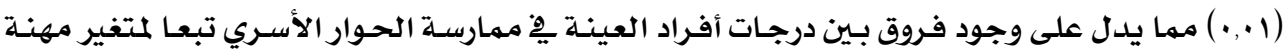

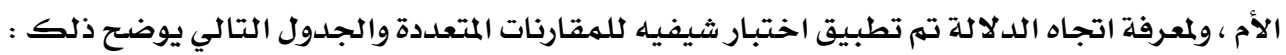
جدول ( ro ) اختبار شيفيه للمقارنات المتعددة

\begin{tabular}{|c|c|c|c|c|}
\hline 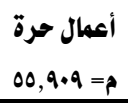 & موظفة قطاع خاص & 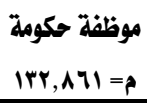 & $\begin{array}{c}\text { لا تعمل } \\
r \cdot ., r \mid Y=\text { r }\end{array}$ & مهنة الأم \\
\hline & & & - & لا تعمل \\
\hline & & - & $* *$ TV,roT & موظفة حكومة \\
\hline & - & $* * V \varepsilon, Y T I$ & $* * \mid \leqslant 1,71 \vee$ & موظفة قطاع خاص \\
\hline- & r.79. & $* *$ V7,90r & $* * \mid \leqslant \varepsilon, r \cdot \Lambda$ & أعمال حرة \\
\hline
\end{tabular}

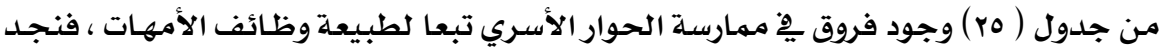

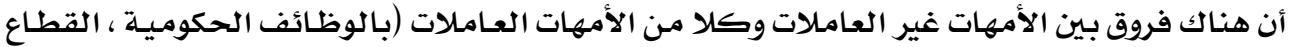

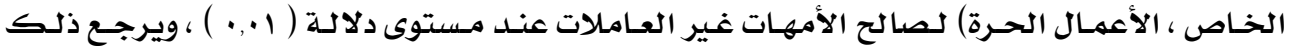


لكون الأمهات غير العامـلات يهضين وقتا أطول مـع أبنائهم وبالتالي يهارسن الحـوار الأسـري أكثر مـن غيرهن من الأمهات .

جدول ( جr) تحليل التباين لدرجات أفراد العينة يــممارسة الحوار الأسري تبعا لمتغير عدد أفراد الأسرة

\begin{tabular}{|c|c|c|c|c|c|}
\hline الدلالة & قيمة (ف) & درجات الحرية & متوسط المربعات & مجموع المربعات & علد أفراد الأسرة \\
\hline \multirow{3}{*}{ ו•,••داJ } & \multirow{2}{*}{ OV, OI\& } & $r$ & 9qrsr, IrV & 191710, ror & بين المججموعات \\
\hline & & Ar & IVYY, rAq & $18107 \mathrm{r}, \mathrm{AV}$. & داخل المججموعات \\
\hline & & $\wedge \xi$ & & $r \xi \cdot r \varepsilon q, r r r$ & المجموع \\
\hline
\end{tabular}

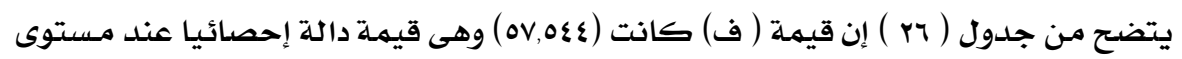

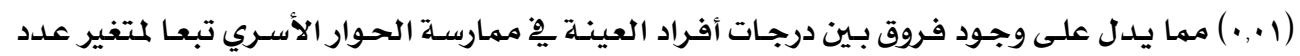

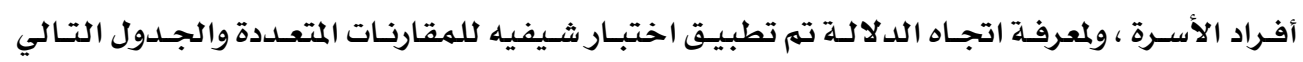
: يوضح ذلك جلول ( ) ) اختبار شيفيه للمقارنات المتعلدة

\begin{tabular}{|c|c|c|c|}
\hline 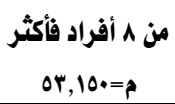 & 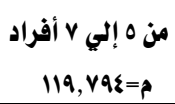 & 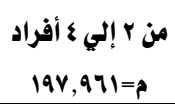 & عدد أفراد الأسرة \\
\hline & & - & من ץ إلي ع أفراد \\
\hline & - & $* * V 1,177$ & من ه إلي v أفراد \\
\hline - & $* * 74,7 \leqslant \varepsilon$ & $* * \mid \leqslant\{, \wedge \mid 1$ & من ^ أفراد فأكثر \\
\hline
\end{tabular}

يتضـح مـن جـــول ( rV ) وجـود فروق يِ مهارسـة الحـوار الأسـري بـين الأسـر مـن r إلىي ع أفراد وكلا من الأسـر (من ه إلي V أفراد - من ^ أفراد فأكثر) لصادح الأسر من ب إلي \& أفراد عند مستوى

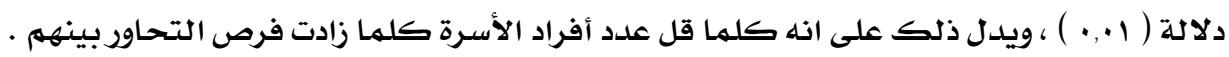

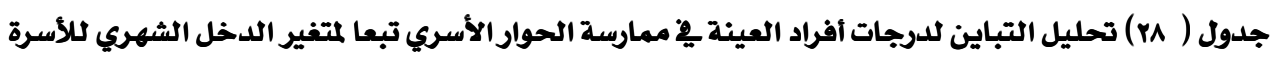

\begin{tabular}{|c|c|c|c|c|c|}
\hline الدلالة & قيمة (ف) & درجات الحرية & متوسط المربعات & مجموع المربعات & الدخل الشهري للأسرة \\
\hline \multirow{3}{*}{ ו•,• داJ } & \multirow{2}{*}{$7 \xi, \Lambda \cdot 0$} & $r$ & $11 \xi 9 \cdot 1, \cdot 7 \xi$ & rraAl7, Irr & بين المجموعات \\
\hline & & Ar & Irrr, I\&q & IEOraA, IVA & داخل المجموعات \\
\hline & & $\wedge \xi$ & & rYOrIE, r.O & المجموع \\
\hline
\end{tabular}

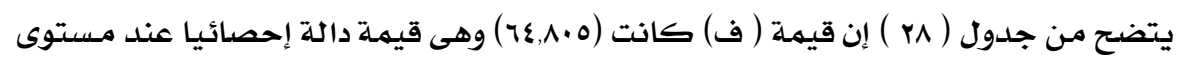

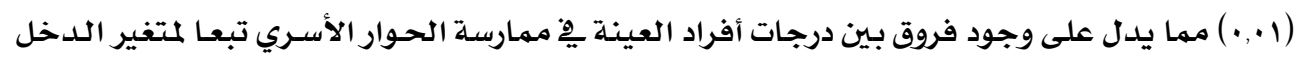
الشهري للأسـرة ، ولمعرفة اتجـاه الدلالـة تم تطبيق اختبـار شيفيه للمقارنات المتعددة والجـدول التـالي يوضح ذلك : 
جدول ( rq ) اختبار شيفيه للمقارنات المتعددة

\begin{tabular}{|c|c|c|c|}
\hline مرتفع & 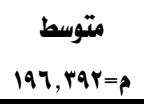 & منخفض & اللدخل الشهري للأسرة \\
\hline & & - & منخفض \\
\hline & - & $* * 0 ., 891$ & متوسط \\
\hline - & $*$ \& IrV,TAY & $\nLeftarrow \leftrightarrow V V, 1 \wedge \varepsilon$ & مرتقع \\
\hline
\end{tabular}

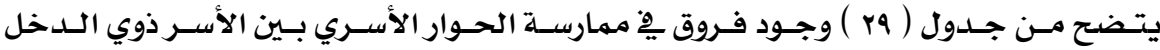

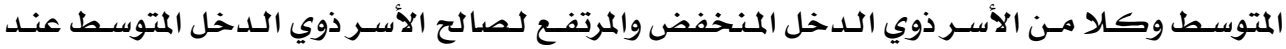

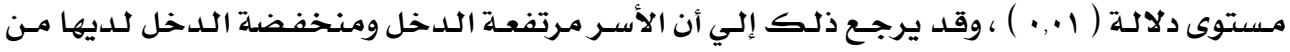

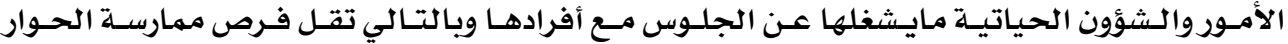
· بين أفرادها أمـا بالنسبة للهـتغيرات الديموغرافيـة للأبنـاء فقـد تم إجـراء اختبـار( ت ) ، وحسـاب تحليل

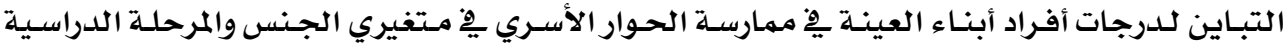
وفقا للجدولين التاليين

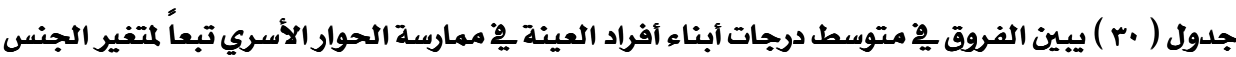

\begin{tabular}{|c|c|c|c|c|c|c|}
\hline الدلالة & قيمة(ت ت & درجات الحرية & العينة & الانحراف المياري & المتوسط الحسابي & الجنس \\
\hline \multirow{2}{*}{ دال عند ا+, • لصالح الإناث } & \multirow{2}{*}{$11, \cdot 0\}$} & \multirow{2}{*}{ Ar } & rq & $I V, A \cdot \xi$ & $97,\{V Y$ & ذكر \\
\hline & & & $\varepsilon 9$ & $r 1,999$ & IrT, rEs & أنثي \\
\hline
\end{tabular}

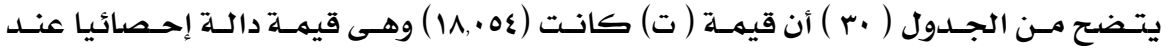

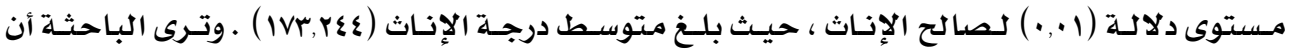

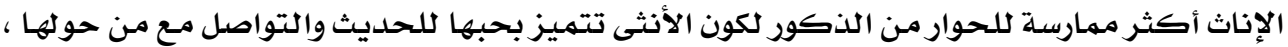

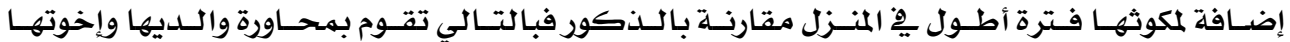
بشكل اكبر •

جدول ( ا ) يبين تحليل التباين لدرجات أبناء أفراد العينة

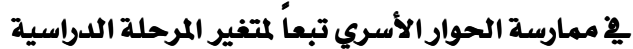

\begin{tabular}{|c|c|c|c|c|c|}
\hline الدلالة & قيمة ( ف) & درجات الحرية & متوسط المربعات & مجموع المربعات & المرحلة الدراسية \\
\hline \multirow{2}{*}{ ו•,•• داJ } & \multirow{2}{*}{$\xi, \bullet \wedge 9$} & $r$ & voroq, rir & rYq.YY, Q૬. & بين المجموعات \\
\hline & & 11 & $\mid v \cdot q, Y O A$ & $|r \wedge \leq \leqslant q, \wedge r|$ & داخل المجموعات \\
\hline & & $\wedge \varepsilon$ & & rYsorv, All & المجموع \\
\hline
\end{tabular}




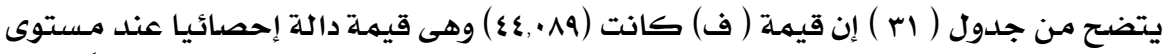

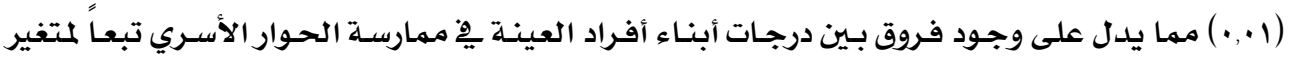

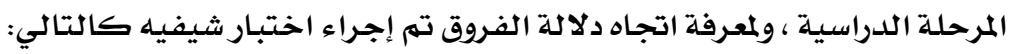
جدول ( مrr) اختبار شيفيه للمقارنات المتعددة

\begin{tabular}{|c|c|c|c|c|}
\hline 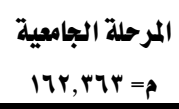 & 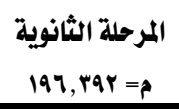 & $\begin{array}{c}\text { المرحلة المتوسطة = } 107 \\
\text { Ar, } 107\end{array}$ & المرحلة الابتدائية & المرحلة اللدراسية \\
\hline & & & - & لمرحلة الابتدائية \\
\hline & & - & $\$ 1 \leqslant, 707$ & المرحلة المتوسطة \\
\hline & - & $* * 11 r, v r 4$ & * * ircrarar & المرحلة الثانوية \\
\hline - & $* * r \varepsilon, r q$ & $\nLeftarrow \nLeftarrow \vee \vee q, \vee \cdot \vee$ & rד, & المرحلة الجامعية \\
\hline
\end{tabular}

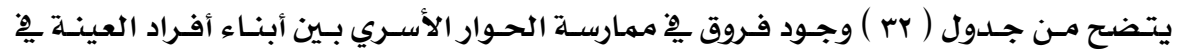

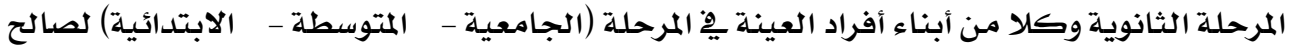

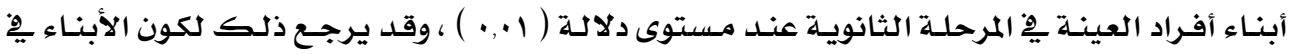

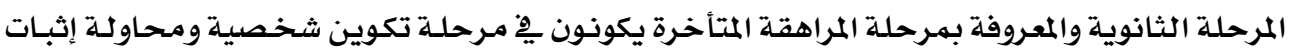

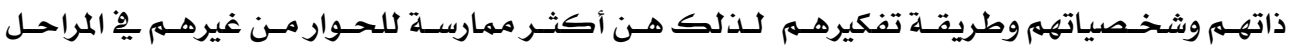

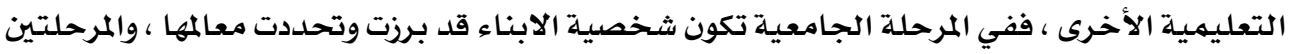

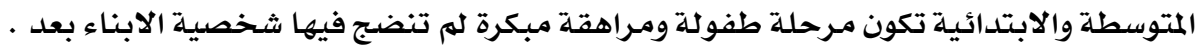
الفرض الثاني : توجد فروق ذات دلالة إحصائية بين متوسط درجـات أفراد العينـة يِّ معوقات الحسوار الأسـري

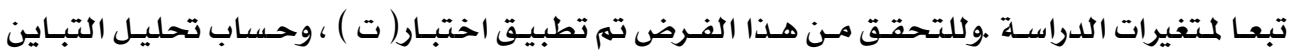

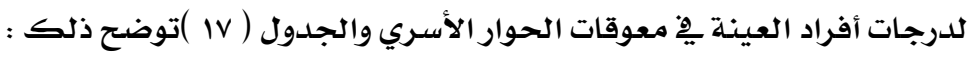
جدول ( r ) تحليل التباين لدرجات أفراد العينة يْ معوقات الحوار الأسري تبعا لمتغير تعليم الأب

\begin{tabular}{|c|c|c|c|c|c|}
\hline الدلالة & قيمة (ف) & درجات الحرية & متوسط المربعات & مجموع المربعات & مستوى تعليم الأب \\
\hline \multirow{3}{*}{ ו•,• دال } & \multirow{2}{*}{ ro,rar } & $r$ & $\wedge \wedge 90,711$ & IYYqI, rrY & بين المجموعات \\
\hline & & Ar & rol,007 & $r+7 r v, 7+1$ & داخل المجموعات \\
\hline & & $\wedge \xi$ & & YAEIA,AYK & المجموع \\
\hline
\end{tabular}

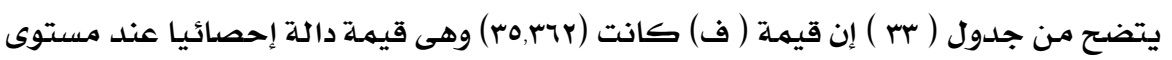

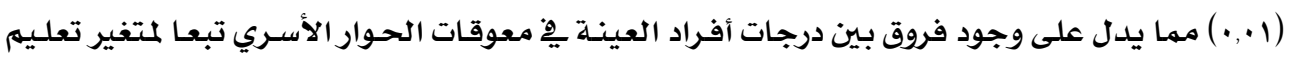

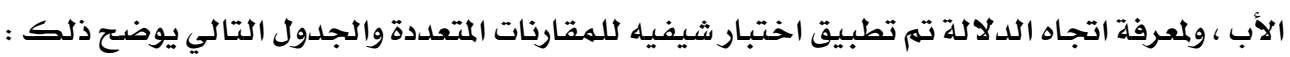


جدول ( ع) اختبار شيفيه للمقارنات المتعلدة

\begin{tabular}{|c|c|c|c|}
\hline $\begin{array}{c}\text { عالي } \\
r 0,1 \vee q\end{array}$ & متوسط & منخفض & مستوى تعليه الأب \\
\hline & & - & منخفض \\
\hline & - & 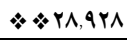 & متوسط \\
\hline - & $* \wedge, \wedge 91$ & $* \nLeftarrow r V, \wedge r$. & عالي \\
\hline
\end{tabular}

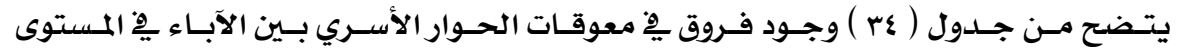

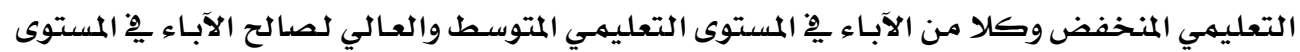

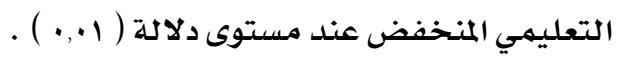

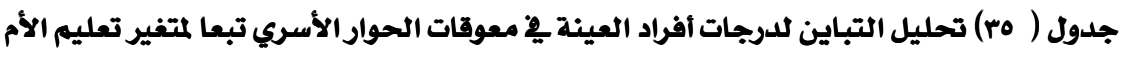

\begin{tabular}{|c|c|c|c|c|c|}
\hline الدلالة & قيمة (ف) & درجات الحرية & متوسط المربعات & مجموع المربعات & مستوى تعليم الأم \\
\hline \multirow{3}{*}{ ו•,•• داJ } & \multirow{2}{*}{ Or,, 000} & $r$ & $\mid \xi \cdot r \cdot, \xi r V$ & $Y \Lambda \cdot \Sigma \cdot, \Lambda V \Sigma$ & بين المجموعات \\
\hline & & Ar & YMI, Yar & rIS7V, rIE & داخل المجموعات \\
\hline & & $\wedge \xi$ & & $\{90 \cdot \wedge, 1 \wedge 1$ & المجموع \\
\hline
\end{tabular}

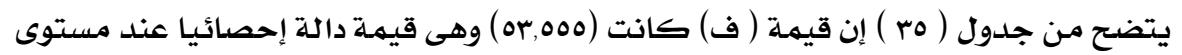

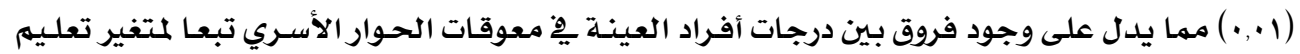

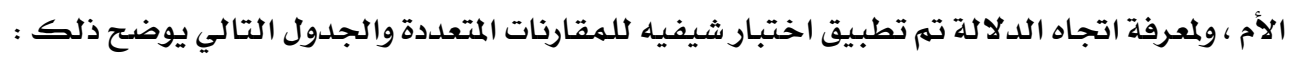
جدول ( م م ) اختبار شيفيه للمقارنات المتعددة

\begin{tabular}{|c|c|c|c|}
\hline عالي & متوسط & منخفض & مستوى تعليم الأم \\
\hline & & - & منخفض \\
\hline & - & $* * 11,0 \vee 1$ & متوسط \\
\hline - & $* * r \cdot, r \wedge 0$ & $* \nLeftarrow \leqslant \wedge, \wedge \circ \vee$ & عالي \\
\hline
\end{tabular}

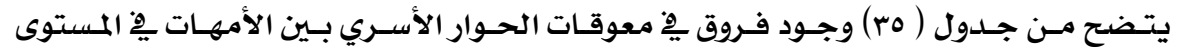

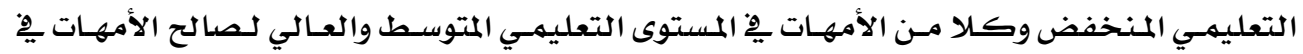

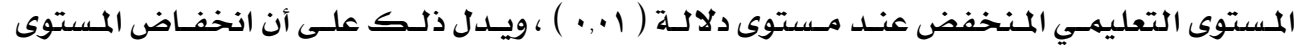

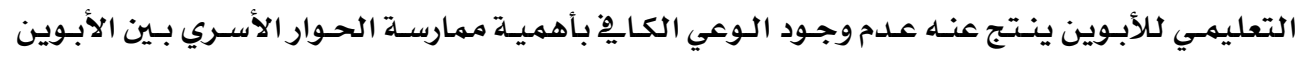

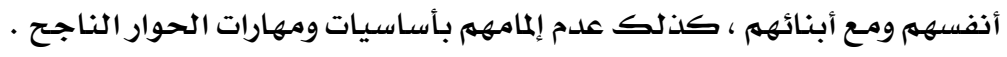


جدول ( س) تحليل التباين لدرجات أفراد العينة فِ معوقات الحوار الأسري تبعا التغير عمر الأب

\begin{tabular}{|c|c|c|c|c|c|}
\hline الدلالة & قيمة (ف) & درجات الحرية & متوسط المربعات & مجموع المربعات & عمر الأب \\
\hline \multirow{3}{*}{ 1•,• داJ } & \multirow{2}{*}{$\mathrm{Y}, \wedge \wedge \mid$} & $r$ & $\Lambda \mid\{r, \cdot \wedge \cdot$ & 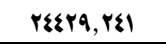 & بين المجموعات \\
\hline & & $\wedge 1$ & $1 v \cdot, \cdot 7 v$ & ITrVo, \$70 & داخل المجموعات \\
\hline & & $\Lambda \xi$ & & $r A r \cdot \xi, r \cdot q$ & المجموع \\
\hline
\end{tabular}

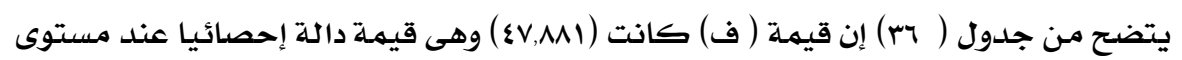

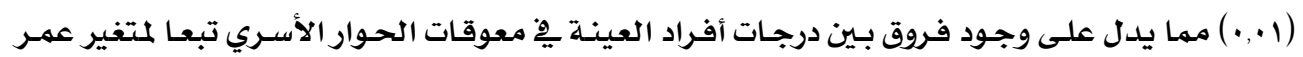

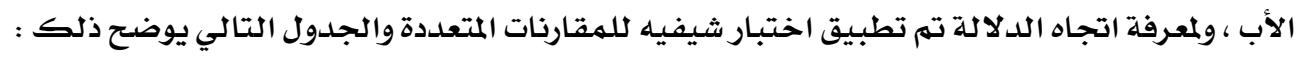
جدول (rv) اختبار شيفيه للمقارنات المتعددة

\begin{tabular}{|c|c|c|c|c|}
\hline من 00 سنة فأكثر & سن هـ سنة لأقل من 00 من & من سنة سنة لأقل من Y & أقل من ro سنة & عمر الأب \\
\hline & & & - & أقل من ro سنة \\
\hline & & - & $* *$ Yo,r人o & من ro سنة لأقل من 0؟ سنة \\
\hline & - & $r, \wedge \varepsilon \varepsilon$ & $* *$ rq,rrq & من 0ـ سنة لأقل من ه0 سنة \\
\hline- & $* * \nvdash \Lambda, * \varepsilon \vee$ & $* * 41,191$ & $* * 0 V, Y V T$ & من 00 سنة فأكثر \\
\hline
\end{tabular}

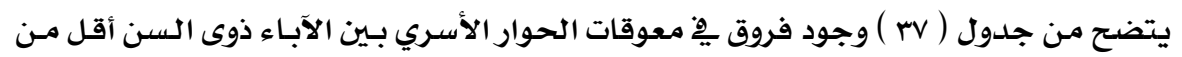

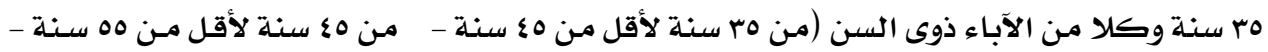

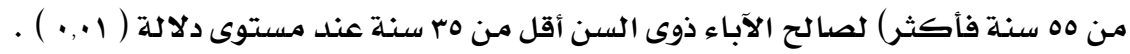

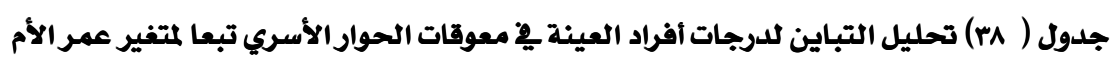

\begin{tabular}{|c|c|c|c|c|c|}
\hline الدلالة & قيهة (ف) & درجات الحرية & متوسط المربعات & مجموع المربعات & عمر الأم \\
\hline \multirow{3}{*}{ ו•,•• داJ } & \multirow{2}{*}{$r q, Y \leqslant V$} & $r$ & $9 \cdot 11, \lambda \cdot 0$ & $r v \cdot r 0, \$ 10$ & بين المجموعات \\
\hline & & $\wedge 1$ & $r \varepsilon 0, r \xi 1$ & $19 \Lambda 7 \xi, 0 Y \wedge$ & داخل المجموعات \\
\hline & & $\wedge \varepsilon$ & & ร7८९9, १०ץ & المجموع \\
\hline
\end{tabular}

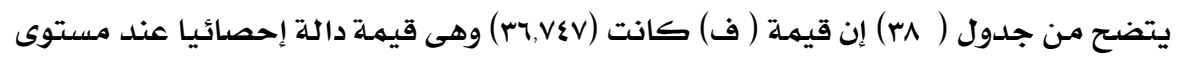

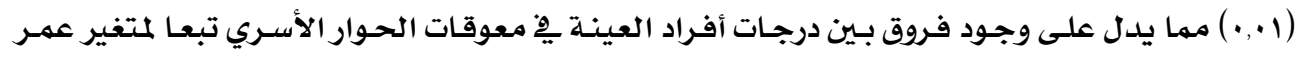

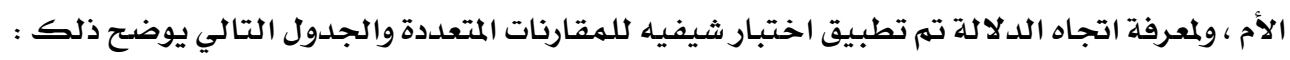


جدول ( q ) اختبار شيفيه للمقارنات المتعددة

\begin{tabular}{|c|c|c|c|c|}
\hline من مه سنة فأكثر & 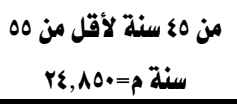 & من سن سنة لأقل من 0؛ & أقل من مr سنة & عمر الأم \\
\hline & & & - & أقل مز مب سنة \\
\hline & & - & $\% * \mid V, V \mu \Lambda$ & من ب سنة لأقل من ه؟ سنة \\
\hline & - & $* *$ r৭,०VA & $* *\{V, r \mid 7$ & من هـ سنة لأقل من ه سنة \\
\hline- & $* 7,7 \ldots$ & $* * 4, I V \Lambda$ & $* \%$ ०4,917 & من ه سنة فأكثر \\
\hline
\end{tabular}

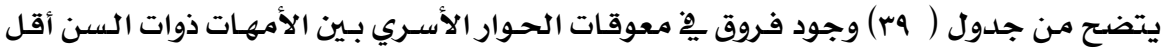

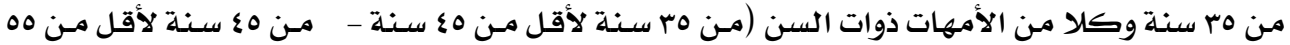

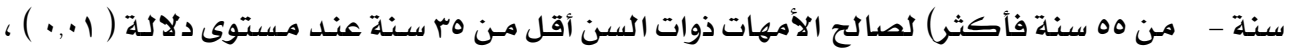

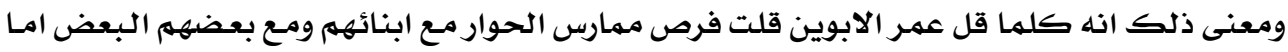

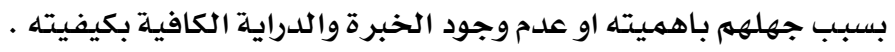

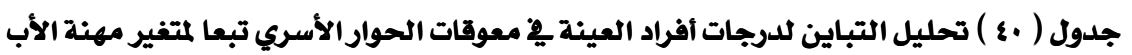

\begin{tabular}{|c|c|c|c|c|c|}
\hline الدلالة & قيمة ( ف) & درجات الحرية & متوسط المربعات & مجموع المربعات & مهنة الأب \\
\hline \multirow{3}{*}{ 1•,• داJ } & \multirow{2}{*}{ ro,..11 } & $r$ & $9 \cdot \vee Y$, YAY & PrrrA,AOQ & بين المجموعات \\
\hline & & Al & roq, ritr & 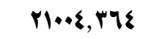 & داخل المجموعات \\
\hline & & $\Lambda \varepsilon$ & & SAYHY,YYY & المجموع \\
\hline
\end{tabular}

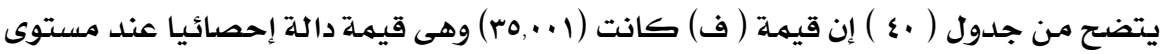

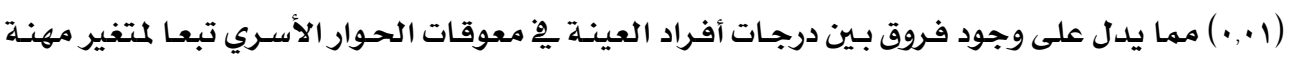

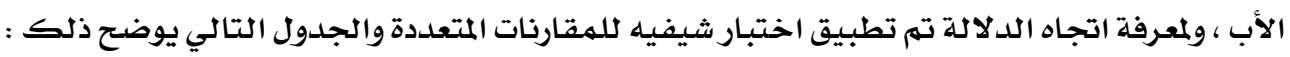
جدول ( اء ) اختبار شيفيه للمقارنات المتعددة

\begin{tabular}{|c|c|c|c|c|}
\hline 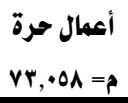 & موظف قطاع خاص & موظف حكومة & $\begin{array}{c}\text { لا يعمل }=8 \\
10,710=\end{array}$ & مهنة الأب \\
\hline & & & - & لا يعمل \\
\hline & & - & $* \nLeftarrow \backslash \Lambda, \wedge \Lambda \varepsilon$ & موظف حكومة \\
\hline & - & $* \& Y V, 0 \ldots$ & $* \& \varepsilon \tau, r \wedge \varepsilon$ & موظف قطاع خاص \\
\hline- & $* * 11, .01$ & 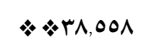 & $* * 0 V, \varepsilon \varepsilon r$ & أعمال حرة \\
\hline
\end{tabular}

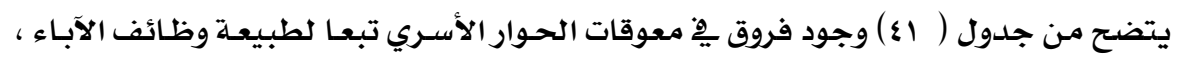

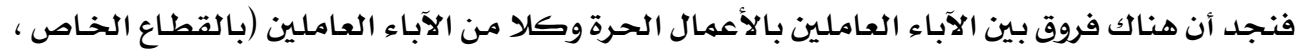

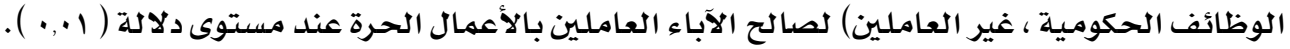


الحوار الأسري : ممارساته ومعوقاته داخل الأسرة السعودية وعلاوقه بيعض المتفيرات

جدول ( ب ) تحليل التباين لدرجات أفراد العينة يُ معوقات الحوار الأسري تبعا لمتغير مهنة الأم

\begin{tabular}{|c|c|c|c|c|c|}
\hline الدلالة & قيمة (ف) & درجات الحرية & متوسط المربعات & مجموع المربعات & مهنة الأم \\
\hline \multirow{3}{*}{ 1•,• داJ } & \multirow{2}{*}{ \&o, r. } & $r$ & QTFI, हVY & rYA9\&,ZTY & بين المجموعات \\
\hline & & $\wedge 1$ & $r \cdot 0, A \mid r$ & $1778 \cdot, 110$ & داخل المجموعات \\
\hline & & $\Lambda \varepsilon$ & & $\sum \leqslant 770, r \leqslant V$ & المجموع \\
\hline
\end{tabular}

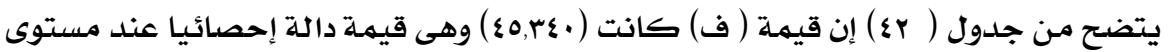

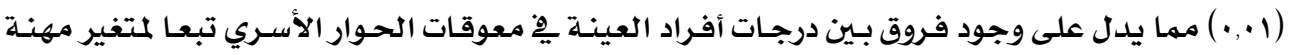

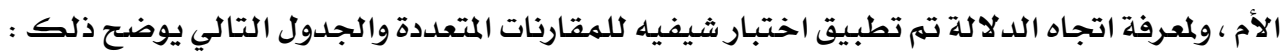
جدول ( اء) اختبار شيفيه للمقارنات المتعددة احيفيه

\begin{tabular}{|c|c|c|c|c|}
\hline 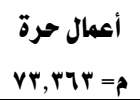 & 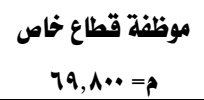 & موظفة حكومة & 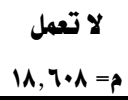 & مهنة الأم \\
\hline & & & - & لا تعمل \\
\hline & & - & $* *$ Y7,^৭1 & موظفة حكومة \\
\hline & - & $* \otimes r \varepsilon, r .$. & $* * 01,191$ & موظفة قطاع خاص \\
\hline- & r.0Tr & $* *$ YV,ATr & $\& \& 0 \leqslant$, VO & أعمال حرة \\
\hline
\end{tabular}

يتضح من جدول ( rع ) وجود فروق يْ معوقات الحوار الأسري تبعا لطبيعـة وظائف الأمهات

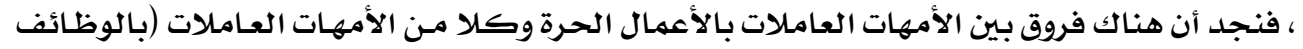

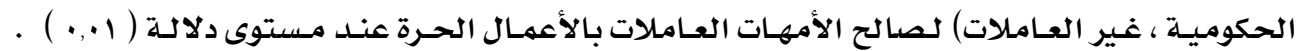

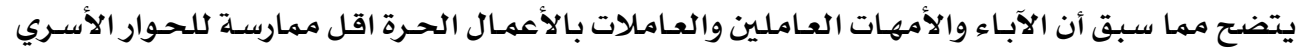

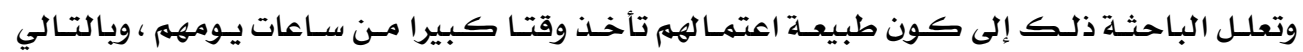

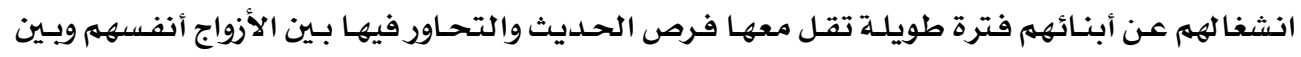

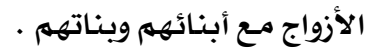

جدول ( §) تحليل التباين لدرجات أفراد العينة يُ معوقات الحوار الأسري تبعا لمتغير عدد أفراد الأسرة

\begin{tabular}{|c|c|c|c|c|c|}
\hline الدلالة & قيمة (ف) & درجات الحرية & متوسط المربعات & مجموع المربعات & عدد أفراد الأسرة \\
\hline \multirow{2}{*}{ 1., ג دال } & \multirow{2}{*}{ §o, rฯ } & $r$ & $1.9 \cdot 1, Y Y Y$ & rMA.r,ZT\& & بين المجموعات \\
\hline & & $A r$ & $r \varepsilon_{0}, \wedge \leqslant 7$ & 19vะq, r\&v & داخل المجموعات \\
\hline & & $\Lambda \varepsilon$ & & $\{1001, A 11$ & المجهوع \\
\hline
\end{tabular}

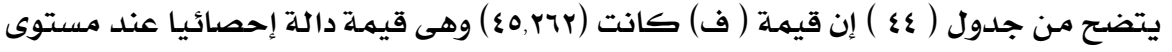

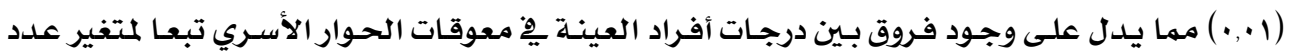

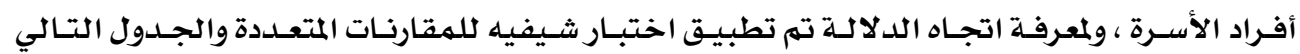
يوضح ذلك : 
جدول ( 0 0 ) اختبار شيفيه للمقارنات المتعددة

\begin{tabular}{|c|c|c|c|}
\hline من 1 أفراد فأكثر & 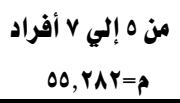 & 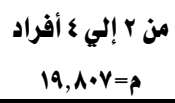 & عدد أفراد الأسرة \\
\hline & & - & من ץ إلي ع أفراد \\
\hline & - & $* * r 0, \varepsilon \vee \varepsilon$ & من ه إلي v أفراد \\
\hline- & $* V, 17 V$ & $* * \leqslant Y, T \leqslant Y$ & من ^ أفراد فأكثر \\
\hline
\end{tabular}

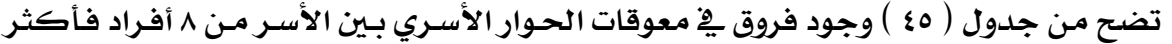

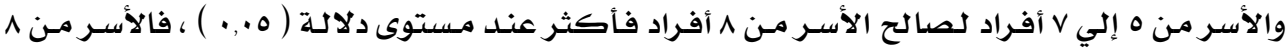

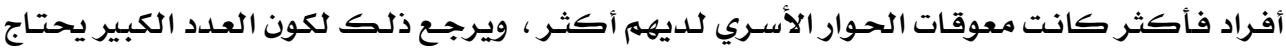

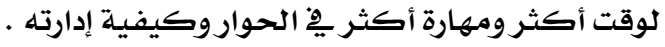
جدول ( وء) تحليل التباين لدرجات أفراد العينة فِ معوقات الحوار الأسري تبعا لمتغير الدخل الشهري للأسرة

\begin{tabular}{|c|c|c|c|c|c|}
\hline الدلالة & قيمة (ف) & درجات الحرية & متوسط المربعات & مجموع المربعات & الدخل الشهري للأسرة \\
\hline \multirow{2}{*}{ ו•,• دال } & \multirow{2}{*}{$\leqslant 9,1 \cdot 9$} & $r$ & $17 r 90,178$ & rYOQ., rYA & بين المجموعات \\
\hline & & Ar & $r A \cdot, q 1\}$ & $Y \Psi \cdot T \xi, T \Lambda \varepsilon$ & داخل المجموعات \\
\hline & & $\wedge \xi$ & & $0.7 r 0, .1 r$ & المجموع \\
\hline
\end{tabular}

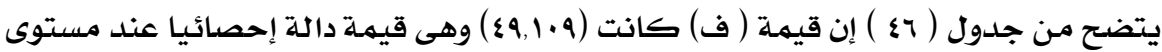

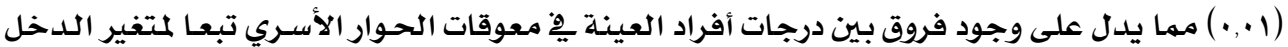

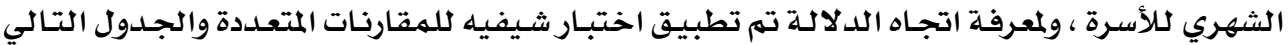
يوضح ذلك :

جدول ( أ ) ) اختبار شيفيه للمقارنات المتعددة

\begin{tabular}{|c|c|c|c|}
\hline مرتفع & 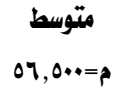 & منخفض & الدخل الشهري للأسرة \\
\hline & & - & منخفض \\
\hline & - & $+\frac{*}{x} 17, \mathrm{ras}$ & متوسط \\
\hline - & $\pm x+1,\{r \mid$ & $x \geq \leqslant \leqslant, \wedge 10$ & مرتفع \\
\hline
\end{tabular}

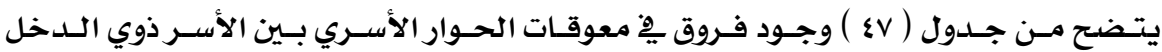

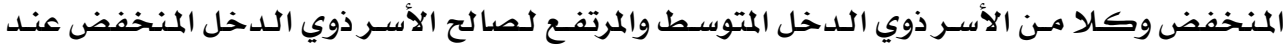

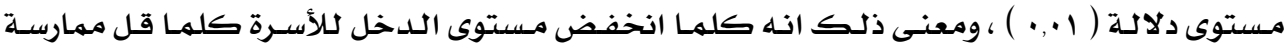

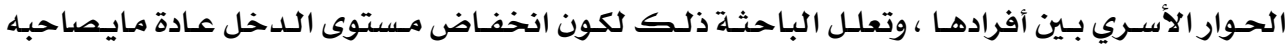

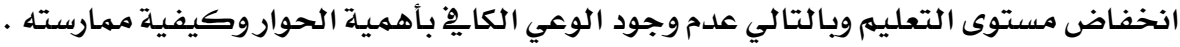




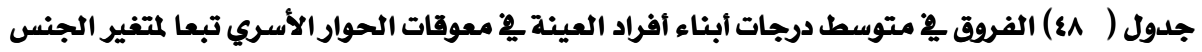

\begin{tabular}{|c|c|c|c|c|c|c|}
\hline الدلالة & قيمة(ت ) & درجات & العينة & الانحراف المعياري & المتوسط الحسابي & الجنس \\
\hline \multirow{2}{*}{ لصال عند ا+, الذكور } & \multirow{2}{*}{$\mid 7, r \xi 1$} & \multirow{2}{*}{ Ar } & rq & $7,7 \cdot 1$ & Tr, Yo. & ذكر \\
\hline & & & $\leqslant 9$ & Ir, TrA & $r \cdot$, rTz & أثي \\
\hline
\end{tabular}

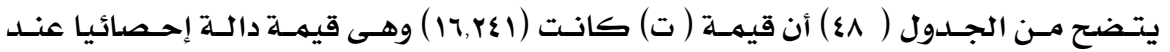

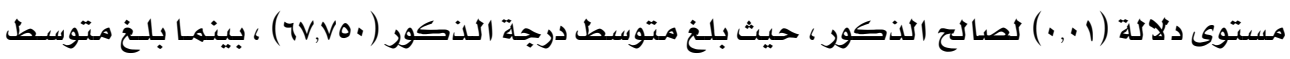

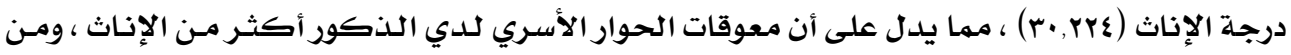

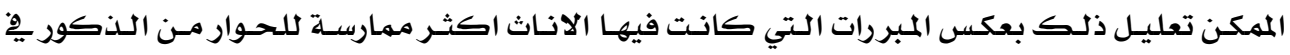

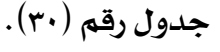

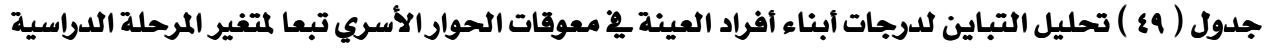

\begin{tabular}{|c|c|c|c|c|c|}
\hline الدلالة & قيمة (ف) & درجات الحرية & متوسط المربعات & مجموع المربعات & المر حلة الدراسية \\
\hline \multirow{2}{*}{ ו•,• גוJ } & \multirow{2}{*}{$r \Lambda, r v r$} & $r$ & ATO.,IrI & ro.0., rar & بين المجموعات \\
\hline & & $A 1$ & MIO,rrA & $|Y \leqslant \varepsilon r, \xi| \varepsilon$ & داخل المجموعات \\
\hline & & $\Lambda \varepsilon$ & & \&r\&AY, rrY & المجموع \\
\hline
\end{tabular}

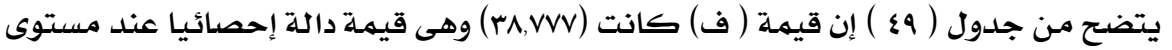

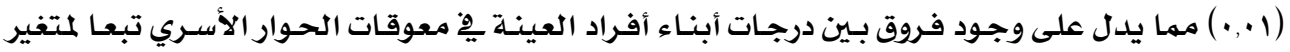

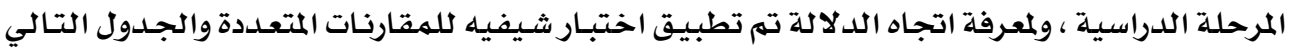
يوضسح ذلك :

جدول ( (0 ) اختبار شيفيه للمقارنات المتعددة

\begin{tabular}{|c|c|c|c|c|}
\hline المرحلة الجامعية & 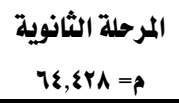 & المرحلة المتوسطة & 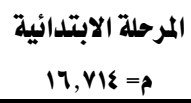 & المرحلة الدراسية \\
\hline & & & - & لمرحلة الابتدائية \\
\hline & & - & $\$ * 1 \Lambda, 794$ & المرحلة المتوسطة \\
\hline & - & $* * r q, \cdot r r$ & $* \otimes \varepsilon V, V) \varepsilon$ & المرحلة الثانوية \\
\hline- & r r r, & 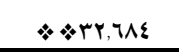 & $* * 01$, rVy & المرحلة الجامعية \\
\hline
\end{tabular}

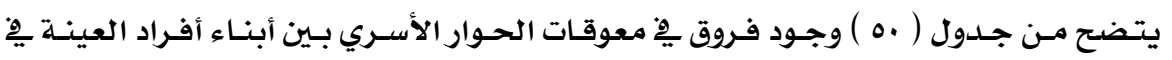

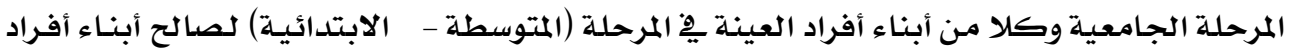

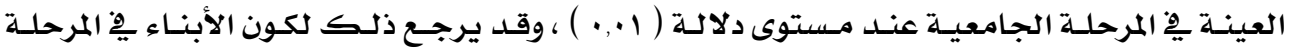

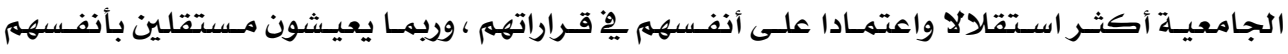
لأسباب دراستهم. 
توجد علاقة ارتباطيه بين محساور استبيان ممارسة الحوار الأسـري ومعوقاته بين أفراد الأسـرة

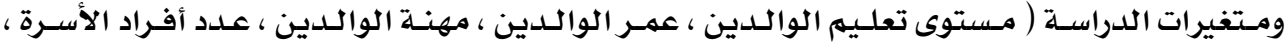

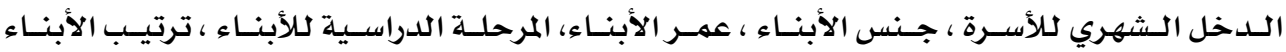

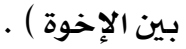

جدول ( 10 ه ) مصفوفة الارتباط بين محاور استبيان ممارسة الحوار الأسري

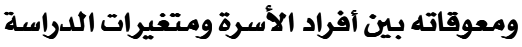

\begin{tabular}{|c|c|c|c|c|c|}
\hline معوقات الحوار & ممارسة الحوار & حوار الأبناء & حوار أولياء الأمور & الدوار الأسري & المتفيرات المستقلة \\
\hline$* * \cdot$, N 0 & $* * .91$. & $\% \cdot 7 \cdot \varepsilon$ & $* * \cdot 110$ & $* * \cdot 9 \mathrm{rV}$ & تعليم الأب \\
\hline$* * \cdot \mathrm{VrV}-$ & $* * \cdot, \wedge \mathrm{VV}$ & $* * \cdot 9 \cdot 4$ & $* * \cdot, \vee \wedge 9$ & $* *, \wedge \wedge$ ד & تعليم الأم \\
\hline • YrY & $\cdot .110$ & $\cdot, 1 \% 9$ & $\cdot r \leqslant 0$ & $\cdot, 1 \cdot 1$ & عمر الأب \\
\hline$\cdot r \cdot r \cdot \varepsilon$ & $\cdot, \mathrm{rV}$ & $\cdot, 117$ & $\cdot, I V Y$ & $\cdot .194$ & 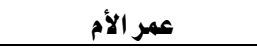 \\
\hline$\leftrightarrow * \cdot 9 r 1$ & $* * \cdot, V \cdot T-$ & $* * \cdot$ VY & $\$, 71 \leqslant-$ & $* * \cdot$ 人т - & علدد أفراد الأسرة \\
\hline$* * \cdot, \cdot, 1-$ & $* * \cdot \mathrm{V} \wedge \mathrm{I}$ & $\star * \cdot \mathrm{VV} \varepsilon$ & $\% \cdot 7 \leqslant V$ & $* * .919$ & مهنة الأب \\
\hline 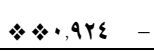 & $* *, \wedge r q$ & $*$, V07 & $\psi * \cdot \wedge \varepsilon \varepsilon$ & r., & مهنة الأم \\
\hline$\cdot, 1 v 0$ & $\cdot$, rir & $\cdot, 11 \mathrm{~V}$ & $\cdot .17 r$ & $\cdot, 1 \wedge \varepsilon$ & اللدخل الشهري للأسرة \\
\hline$\cdot, 1 \leqslant r$ & $\cdot .17 \mathrm{~V}$ & ( & $\cdot, 19 \varepsilon$ & $\cdot 1.0$ & الجنس \\
\hline$* *$, V90 - & $* * \cdot \mathrm{VIr}$ & סשד, •*. & $* * \cdot V \mu 1$ & $* *, \wedge 0 \varepsilon$ & عمر الأبناء \\
\hline$* *, \wedge \leq 7-$ & $* *, \wedge \vee \wedge$ & $* * \cdot 9 \leqslant r$ & $\% \cdot 7 \cdot 9$ & $* * \cdot \wedge Y T$ & المرحلة اللدراسية \\
\hline .107 & $\cdot, \mid r \varepsilon$ & $\cdot, 119$ & - rro & . & ترتيب الأبناء بين الإخوة \\
\hline
\end{tabular}

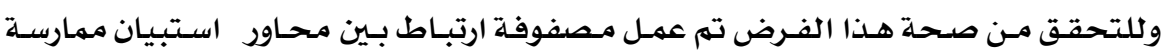

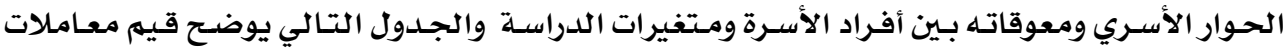
الارتباط :

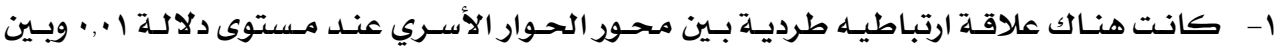

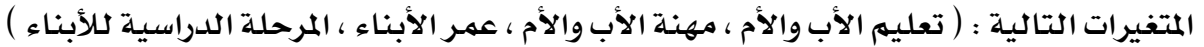

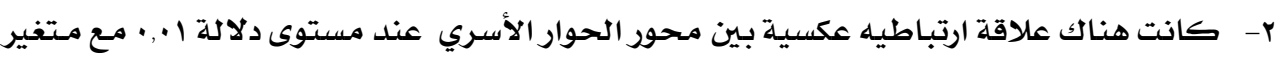

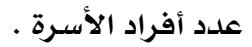

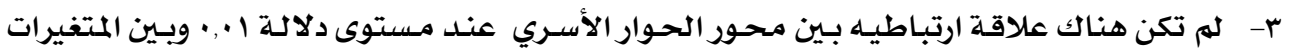

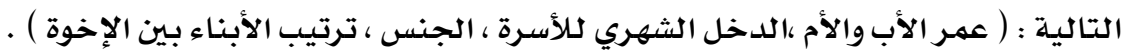

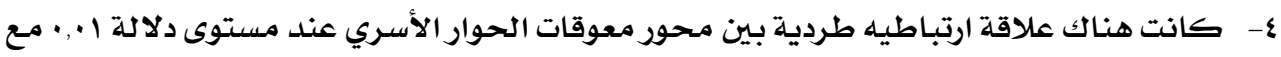
متغير عدد أفراد الأسـرة . 


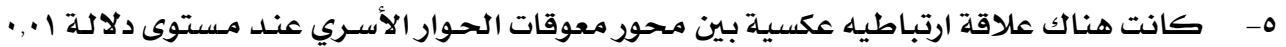

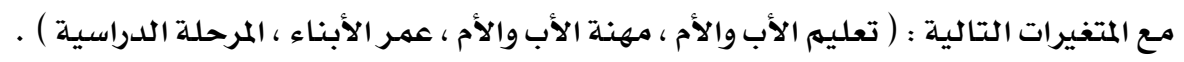

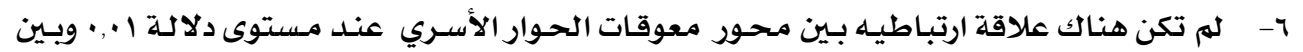

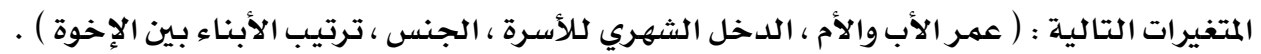

\section{الفرض الرابع :}

تختلف نسبة مشاركة العوامل المؤثرة على ممارسـة الحوار الأسري بين أفراد الأسرة .

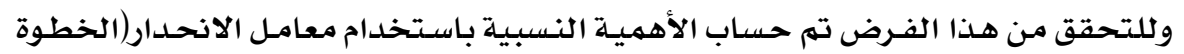

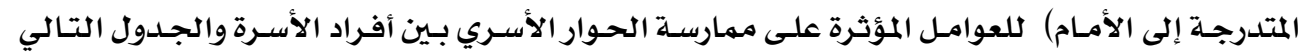
يوضح ذلك :

جدول ( 19 ) يبين الأهمية النسبية باستخدام معامل الانحدار

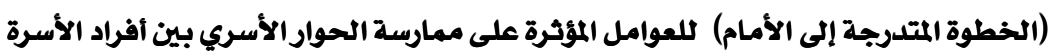

\begin{tabular}{|c|c|c|c|c|c|c|c|c|}
\hline الدلالة & 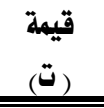 & الانعدار & الدلالة & قيمة ف) & نسبة & معامل الارتباط & المتفير & छ․ \\
\hline$\bullet,+1$ & 10,rry & $\cdot, 1 \cdot 9$ & $\cdot, \cdot 1$ & rrr,IET & •,Arq & $\cdot, 91$ & تعليه الأب & E: \\
\hline$\bullet,+1$ & Ir,rra & $\cdot, \vee 770$ & $\cdot, \cdot 1$ & Irv, IIV & •, rAv & $\cdot, \wedge \wedge \vee$ & تعليم الأم & $\underline{-}$ \\
\hline$\cdot, \cdot 1$ & 1., TAr & $\cdot, 7 \Lambda$. & $\cdot, \cdot 1$ & $11 \varepsilon, 1 \%$. & $\cdot, V \cdot \varepsilon$ & •, Arq & مهنة الأم & $\bar{E}^{2}$ \\
\hline$\bullet,+1$ & A, yor & $\cdot, 0 \wedge \varepsilon$ & $\cdot, \cdot 1$ & $\vee \xi, \wedge \neg 1$ & $\cdot, 7 \cdot 9$ & $\cdot, Y A I$ & مهنة الأب & $=$ \\
\hline
\end{tabular}

كان مـتغير تعلـيم الأب مـن أكثر العوامـل المؤثرة على ممارسـة الحسوار الأسـري بـين أفراد

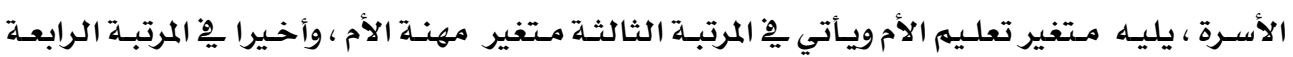

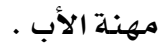

ا - عقد ندوات تثقيفية ودورات تدريبيه للمقبلين على الزواج لتوعيتهم بأهمية الحوار الأسري .

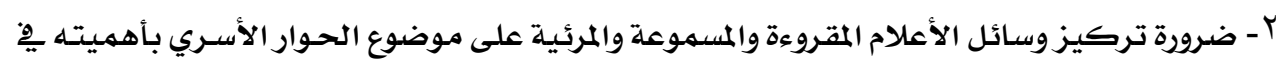

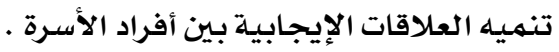
"- تفعيل دور الاستشاريين الأسريين ونشر ثقافة التعاون معهمه ·

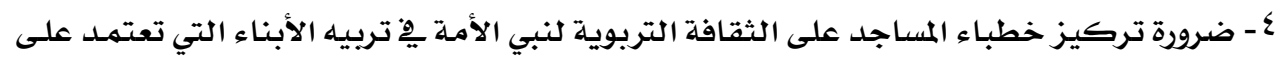

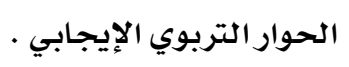

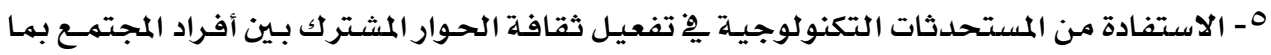

$$
\text { يناسب تقاليده وعاداته . }
$$

7 - ضرورة تكاتف مؤسسات المجتهمع مـع الأسرة للاهتمام بتنمية ثقافة الحوار . 


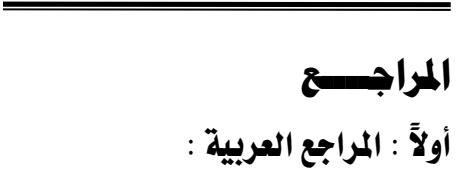

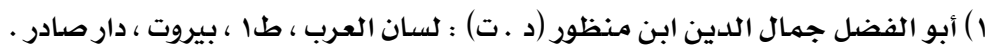

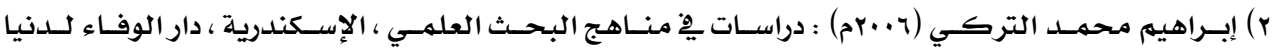

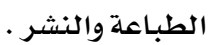

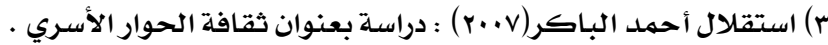

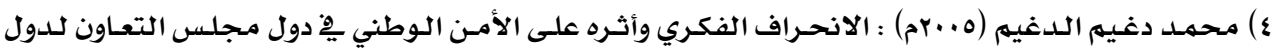

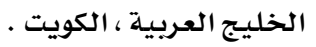

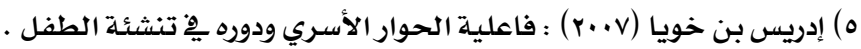

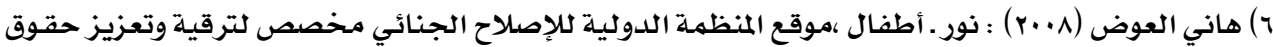

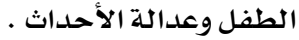

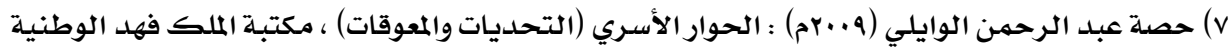

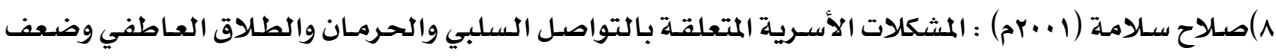

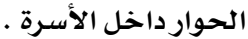

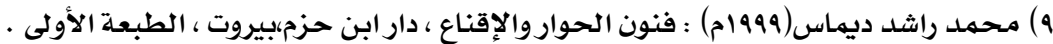

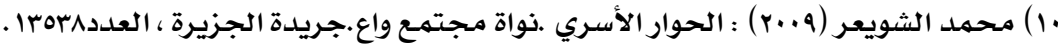

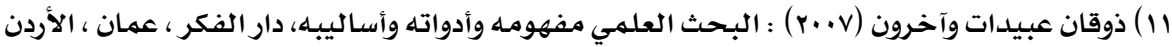

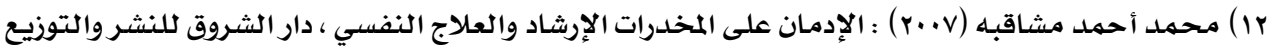

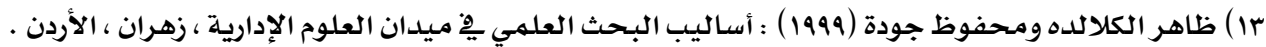

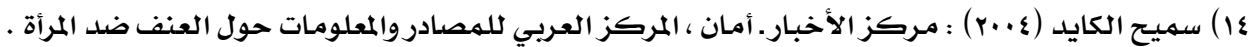

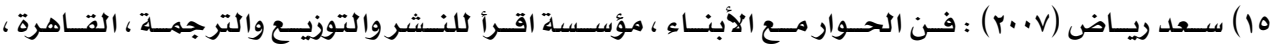

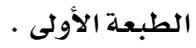

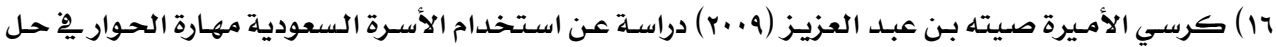

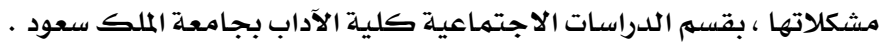

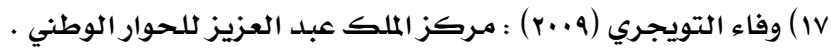

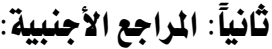

17) Lippincott Williams (2008) "A Transactional ,family centered approach to enhancing communication and socioemotional abilities of children.

18) Wiley interscience -journals-family process(2008) : "family structure versus family relationships for prediciting to 